\title{
The Star-Beings and stones: Petroforms and the reflection of Native American cosmology, myth and stellar traditions
}

\author{
Herman E. Bender \\ The Hanwakan Center for Prehistoric Astronomy, Cosmology and Cultural Landscape Studies, Inc., Fond du \\ Lac, Wisconsin, U.S.A. Email: ashco@charter.net
}

\begin{abstract}
:
Native American myths, legends and oral traditions are rich with stories of giant beings existing in ancient times. They all talk of giant Thunderers or Thunder-beings, giant snakes and great Thunderbirds. Even the first humans were said to be giants, some half man, half animal. The Tsistsistas (Cheyenne) have a name for the giant beings that their ancestors encountered during the early migration to the grasslands of the Great Plains. They called them haztova hotoxceo or "twofaced star people". Other Plains tribes such as the Black Feet, Gros Ventres and Lakota have similar stories.

These old stories may have real world counterparts. Discovered in a prehistoric effigy-mound group (the Kolterman Mounds) in south-eastern Wisconsin (U.S.A.) is a human-like petroform or lithic effigy with a serpentine body and wing-like arms known as the 'Star-being'. Configured in stone, it is approximately 20 metres in length with a red coloured, bison-shaped headstone aligned to face the summer solstice sunrise. However, it is not a lone or singular occurrence. The 'Star-being' is but one of two human-like petroform effigies discovered in south-eastern Wisconsin. There is another of almost the same size called the Starman which also has a red coloured, bison-shaped headstone aligned to face the summer solstice sunrise. Both the Starman and Star-Being lithic complexes are codified by the State Historical Society of Wisconsin as archaeological sites of Archaic age.

Each giant lithic effigy appears to be a reflection of certain constellations and stars. The 'Starbeing' is a mirror-image of the (western) constellations of Scorpius and Libra (with Sagittarius); the Starman is an almost exact representation of Taurus and the Pleiades. Both giant effigies are estimated to be 3500-6000 years old, embodiments of ancient legends and traditions writ large in stone and connected to 'The People' through ceremony and acts of cosmic renewal.
\end{abstract}

Keywords: headstone; Massaum; petroform; Star-Being; Wisconsin

\section{Introduction}

To find the origin of many Plains Indians traditions, one needs to look to the east whence they came. The 'text book' Plains Indians, generally the macro Sioux, Cheyenne, Arapaho, Assiniboine, Crow and other related tribes migrated west to the Plains area from the upper Great Lakes area. Some were woodland-adapted, others lived on the prairie and woodland border areas of southern Wisconsin and Minnesota. No matter the later tribal affiliation, all

Published by the School of History, Classics and Archaeology, University of Edinburgh ISSN: 2055-0472. URL: http://journals.ed.ac.uk/lithicstudies/

This work is licensed under a Creative Commons Attribution 2.5 UK: Scotland License. 
had been settled in the northern and western Great Lakes area for untold generations. They were either proto-Algonquin or proto-Siouan speaking people who, living close to each other for generations, developed a similar lifestyle and common culture despite the differing language core (Bender 2004: 14; Hewes 1948; Powers 1977: 18; Waldman 1985: 39-40, $67-$ $68)$.

When they migrated west, 'the people' as most called themselves did what others have done during their migrations or journey of nations; they took their beliefs and traditions with them. Because of this, many ancient traditions, beliefs and ceremonies practiced on the Plains retained ties to their earlier origins in the east (Powell 1969: 26; Schlesier 1987: 50-51; Taylor \& Sturtevant 1996: 136-139).

Retained in the (transported) traditions are stories related to the stars. It is these ancient stories that form a foundation for the Plains Indian cosmologies. How the cosmologies developed and then established through ceremony was timed to natural and celestial events. Some or parts of the Plains Indian cosmological view linking 'the people' to the universe may well be found in two petroform sites in south eastern Wisconsin. Petroforms (or lithiforms) are best described as geometric or effigy forms constructed with large rocks or small boulders and used for ritual purpose (Behm et al. 1989; Bender 1992; Steinbring 1970a; Steinbring et al. 1995; Steinbring et al. 2003).

Together with petroglyphs and pictographs, petroforms are considered a form of rock art (Steinbring 1999; Steinbring \& Buchner 1997: 73-84). To create most such forms, individual rocks were intentionally placed on the land surface to form an outline or particular shape, e.g. a circle or turtle, but in some cases selective removal of rocks laid down by random (glacial) scatter may have been employed, thus achieving the desired shape. Both the Starman and Star-Being were made by careful positioning of rocks on the land surface.

Petroforms were first mapped and examined in North Dakota, South Dakota, Minnesota and Iowa by T.H. Lewis $(1886,1889,1890$ and 1891). Lewis recognized the antiquity of the forms by how deeply the individual rocks composing the petroform were embedded in the prairie soil. Cyrus Thomas (1894: 35) noted that the "boulder" [petroform] sites were "found upon the highest lands of the Missouri and James rivers and their tributaries" linking their occurrence to prominences and rivers. Few reports followed. It was almost a century before attention to petroform once again entered the mainstream of rock art research with the rediscovery of the Tie Creek Site in southeastern Manitoba, Canada (Steinbring 1970a, Steinbring et al. 2003: 111-112; Sutton 1965).

A few years later at the Big Horn (Wyoming) and Moose Mountain (Saskatchewan) 'medicine wheels' (Brumley 1988), both large petroform sites, field investigations were conducted to test proposed solstice and stellar alignments of these stone monuments (Eddy 1974; 1977). Moose Mountain was dated as early as 500 BCE based on Eddy's heliacal star rise calculations, a date later supported by carbon dating (Kehoe \& Kehoe 1977: 86).

Then in 1986, the Krug-Senn petroform site was discovered in the Kettle Moraine landscape of southeastern Wisconsin (Behm et al. 1989). A complex site with three distinct loci, it included the easternmost, solstice and equinox-aligned 'medicine wheel' known in North America, effigy and geometric shape boulder arrangements, standing stones, earthen mounds and more. Because there was little to no available literature or experience on how to scientifically investigate a complex petroform site with suspected astronomical alignments and, associated with it, an environmental interaction sphere containing late Archaic age (3000-1000 BCE) hilltop shrines with attributes of mutual visibility over distance (Steinbring et al. 1995: 22-23), a new paradigm and methodologies beyond excavation had to literally be invented.

Furthermore, all needed to be relevant to the geologic history, climate and Native American astronomy traditions and cosmologies indigenous to the upper Midwest and 
northern grasslands of the North American mid-continent, not the American desert southwest or meso-America (Bender 2007).

\section{Practical Factors and Methodology}

During the six years spent investigating the Krug-Senn petroform and archaeoastronomy site (1986-1992), the methods needed to objectively assess whether ancient Native American astronomical attributes and observations were a primary function of a petroform site were eventually developed (Bender 2008a). These methods were further developed with the discovery and investigations of both the Starman and Star-being petroform sites and their apparent stellar attributes (Bender 2004; 2008b; 2011a). Logically, if astronomical alignments are suspected or detected, a practical working knowledge of astronomy basics is essential.

The basic astronomical skills brought to an investigation should include, but are not limited to, a knowledge or familiarity with: (1) the night-sky realm including constellation and individual bright star and planet recognition or identification together with their seasonal movements over time; (2) stellar colours and magnitude values as indicated by the Hertzsprung-Russel diagram (Abel 1984: 288, A.38); (3) celestial coordinate systems (Abel 1984: 57-61); (4) solar and lunar cycles apparent from Earth and their seasonal movement against the background of stars, i.e. the concept of the Zodiac (Cornelius 1997); (5) astronomical algorithms and their mathematical base (Meeus 1991; 1997); (6) astronomical terms and nomenclature (Abel 1984: A.5-A.26), and (7) familiarity with star charts, maps and ephemerides.

Furthermore, years of observational experience working within the limits of unaided or naked-eye astronomy is of critical importance and, perhaps, the best experience that one can possess when working in the field of archaeoastronomy, a field of study inherently within the limits of unaided eye observations (Bender 2008b; 2011a).

Because Wisconsin is part of the heavily glaciated North American mid-continent which is a relatively recently formed late Ice Age landscape (Clayton et al. 1991; LaBerge 1994: 249-299; Syverson \& Colgan 2011: 537), geological factors should include but are not limited to: (1) knowledge of late Pleistocene geology, glaciation and local glacial dynamics; (2) knowledge of lithic identification, sources and ice transport; (3) Bowen's reaction series and how when applied to differential weathering profiles (Bloom 1978: 120; Ehlers \& Blatt 1982: 147-157, 270-272), and (4) Holocene climate, vegetation and megafauna shifts over time (Bender 2007).

Cultural factors should include but are not limited to knowledge of (1) both ancient and resident indigenous populations (Quimby 1960); (2) prehistoric and historic era settlement patterns (Waldman 1985: 39-40); (3) tribal migration histories (Taylor \& Sturtevant 1996: 136-139); (4) macro-language group core areas and oral traditions (Powell 1969: 26; Schlesier 1987: 50-51; Waldman 1985: 67-68); (5) oral traditions, stories and beliefs based on generations of observation of the natural world, especially those with astronomical events or direct links to celestial observations and the development of a cosmology (Bender 2011a; 2011b; Goodman 1992; Schlesier 1987).

On the physical landscape, field research in the Kettle Moraine and former prairie areas coupled with an intensive field survey (Bender 1995a; Steinbring 1997; Steinbring et al. 1995) had clearly demonstrated the development and placement of 'trail shrines' (Bender 1995a; Blakeslee \& Blasing 1988). These shrines were located along the trails or footpaths connecting river headwaters, drainage divides and springs at the base of prominent hills. The hills exhibited not only prominence, a phenomenal attribute (Steinbring 1992), but aspects of mutual visibility one to another (Bender 1995a; 2008a; 2011b; Steinbring 1992; 1997; Steinbring et al. 1995). Both the spring areas at the base of the hills and the tops of the hills 
became favored locations for rock art, petroform or boulder effigies, Manitou or standing stones, bison-effigy rocks, and cairns. Many of these 'trail shrines' apparently date from the mid to late Archaic, ca. 3000 to 1000 BCE with some likely older (Bender 1995a; 2008a; Steinbring 1997; Steinbring et al. 1995; Steinbring \& Buchner 1997).

In addition to the trail, an intensive survey had clearly demonstrated that potential existed for the discovery of what we had labelled "heritage phenomena" (Bender 1995a; Steinbring et al. 1995). Heritage phenomena can include but are not limited to prehistoric cultural remains (such as artifacts, petroform, mounds, etc.); a historic and ethnic presence; aboriginal environmental 'interaction areas' which include springs, hilltops, vistas, astro-archaeological sight-lines and the general quality of horizontal aesthetics viewed from hilltops plus other intangible rather than physical remains (Bender 1995a; 2008a; 2011b; Steinbring 1992; Steinbring et al. 1995).

Included in the heritage phenomena was the recognition of an Archaic-age lithic artifact association and the select locations for shrine sites indicating a 'definite Archaic presence' imprinted on the cultural landscape of the Kettle Moraine (Bender 1995a; 2008a; 2011b; Steinbring 1997).

Development and utilization of the parameters and methodology inherent in the cultural landscape model represented a distinct paradigm shift on how to approach the investigation of sites on the cultural landscape. Furthermore, because of the proven association of trails with springs, prominence, river headwaters and drainage divides, there was a predictive component within the model if these factors came together in one area. They did in eastern Fond du Lac County and set the stage for the discovery of the Starman site.

Prior to my first field visit after being invited to assess some suspected standing stones on a nearby property, topographic map analysis and archival research were employed. Through an interview with one local landowner and his neighbours, many of them farmers who had lived in the area since before World War II, information was relayed that a trail or footpath did indeed skirt the marsh on the east base of a 'target' hill that I had previously determined would be 'of interest'. This hill was of interest because springs at its base fed the headwaters of both the Sheboygan and Milwaukee rivers forming part of a drainage divide. Along with the trail, prominence, springs, river headwaters and the divide were important criteria in the parameters of the field model's predictive qualities. If the hill was found to be uncultivated never having been cleared for agricultural purposes, the possibility of discovering an intact, prehistoric trail shrine at its base or on its summit existed.

However, the initial plan was to go there to survey and ascertain whether or not it held promise of containing 'petroform' and to confirm whether any remnants of a pre-settlement 'Indian' trail or footpath were still visible. It was on the morning of my first visit that, with field books and compass in hand, I walked into and discovered what would later be named the 'Starman' site.

\section{The Starman and site description}

The Starman, which is a petroform and archaeoastronomy site complex, is located in eastern Fond du Lac County (Figure 1). The Starman petroform (from which the site takes its name) is a very masculine, approximate 17 metres (55 feet) long, stickman-shaped effigy bearing an atlatl (Figure 2).

The complex occupies a small hill which affords a $360^{\circ}$ panoramic view from the hilltop (Figures 3 and 4). Some vistas are now partially obscured by trees and brush, but during the time of the much warmer and drier Climatic Optimum approximately 7000-3000 years ago, the area was far more open with few trees (Bender 2007: 7; Goldstein 1983: 39; Goldstein \& 
Kind 1983; King 1981), a prairie landscape with oak openings which persisted on for millennia (Denevan 1992).

Remnant vestiges of a more open landscape with widespread prairie and interspersed oak savannah were recorded in the 1830s by the Government Land Office surveyors (Figure 1).

\title{
Early Vegetation of Wisconsin
}

\author{
University of Wisconsin Extension \\ Geologic and Natural History Survey
}

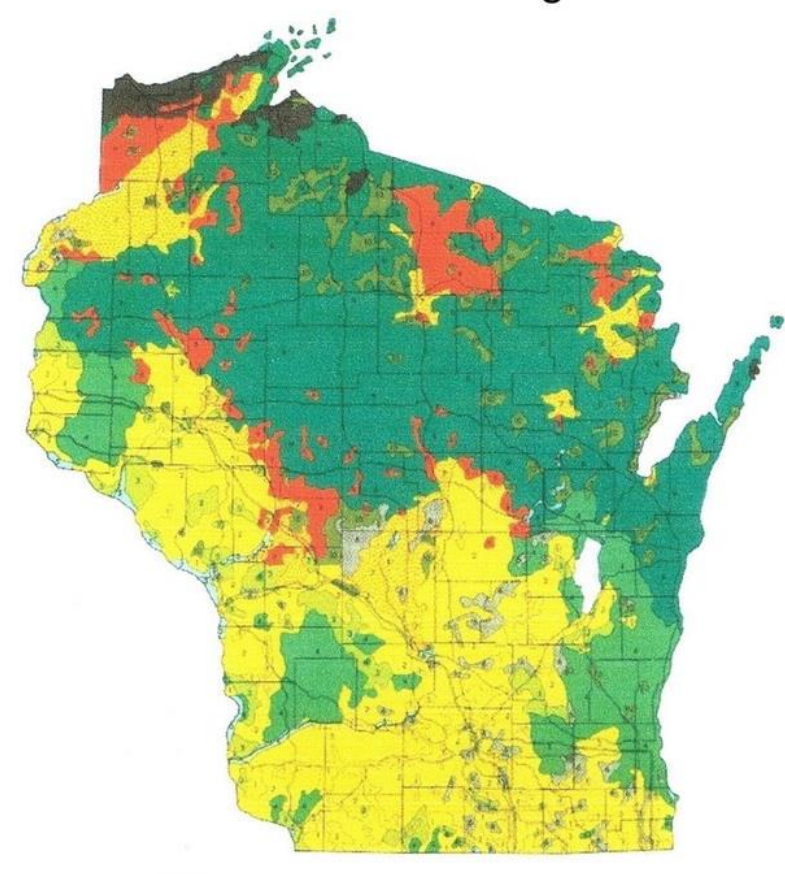

\section{Legend}
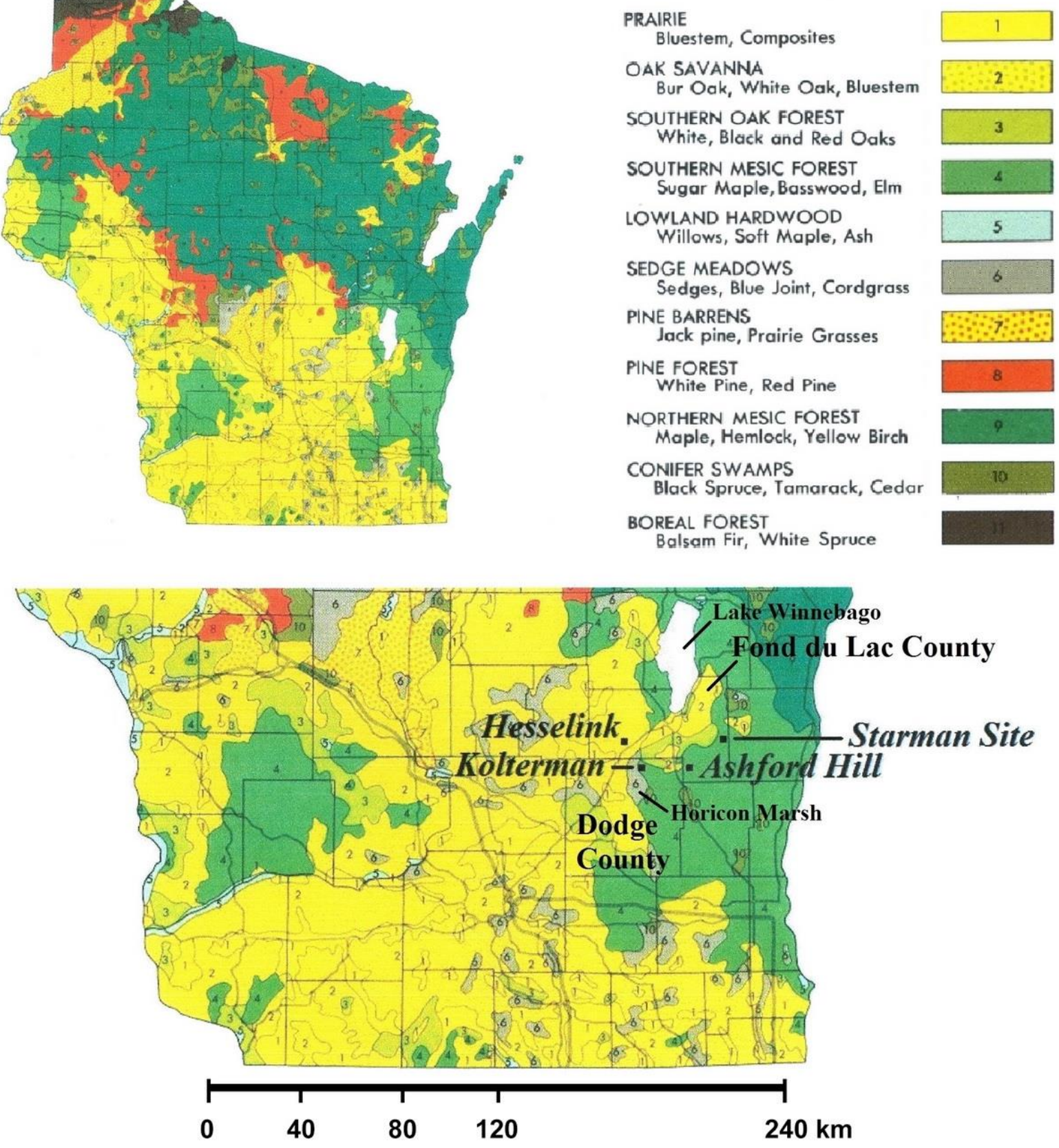

Figure 1. Pre-settlement vegetation map of southern Wisconsin with the locations of important bison effigy and petroform sites. Fond du Lac and Dodge Counties are marked. Note that the areas coloured yellow (Nos. 1 \& 2) in the southern part of Wisconsin are prairie and oak savanna, both open grassland landscapes. 


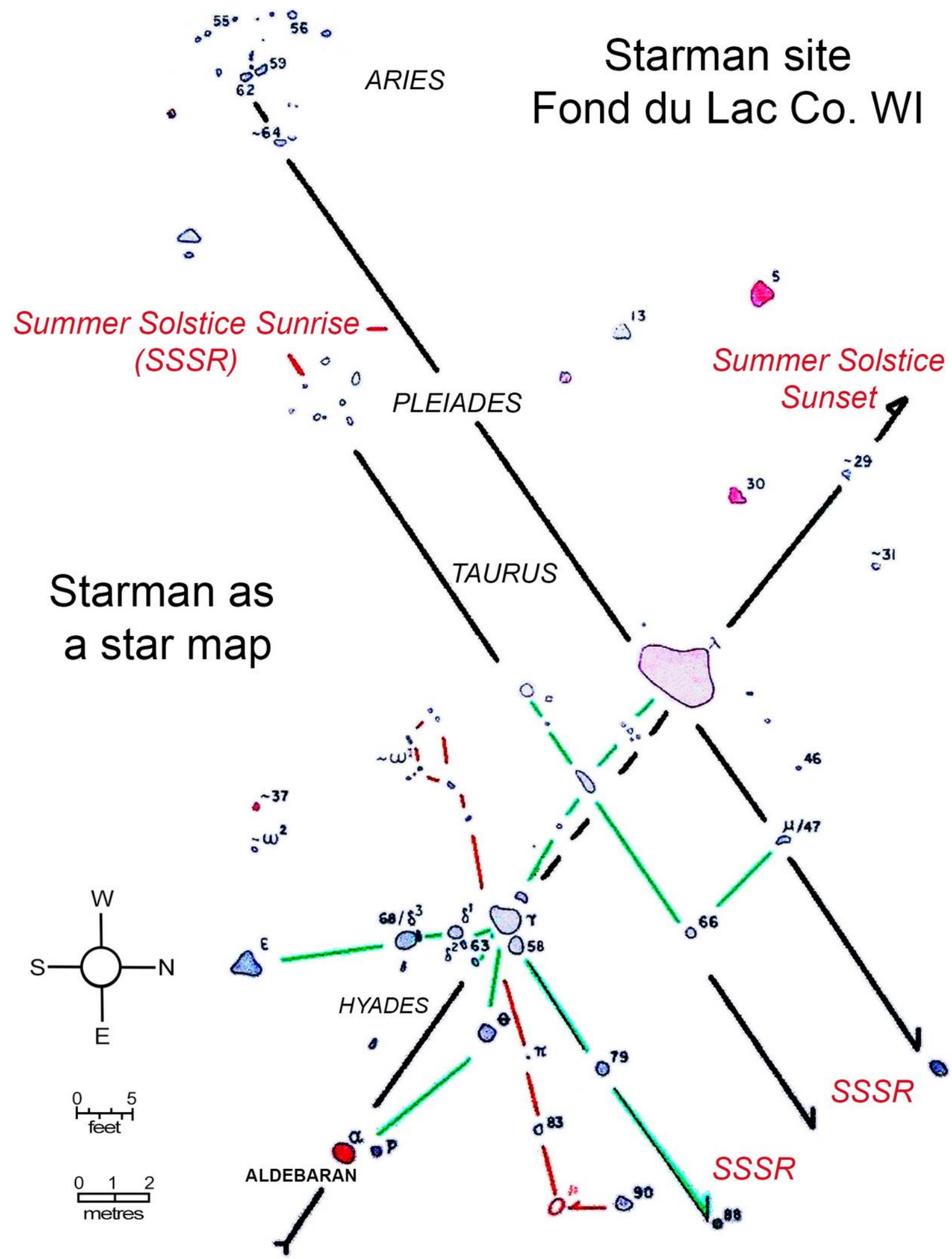

Figure 2. Partial map of the Starman site as a star map illustrating its astronomical attributes. Note the redcoloured, summer solstice sunrise aligned, bison-shaped headstone (see Figure 9), the parallel, multiple summer solstice sunrise alignments, and the rock-for-star designations of the individual rocks directly compared to a star chart. A red coloured rock was strategically placed to indicate the red star Aldebaran. The rock in the 'pelvis' of the Starman is a recumbent Bison Stone also aligned to face the summer solstice sunrise (Figure 10). All the proposed solstice alignments have been observed and photographically confirmed. Each exhibits the full solar disk shift consistent with 3500-4000 years of the shift of the obliquity of the ecliptic. 


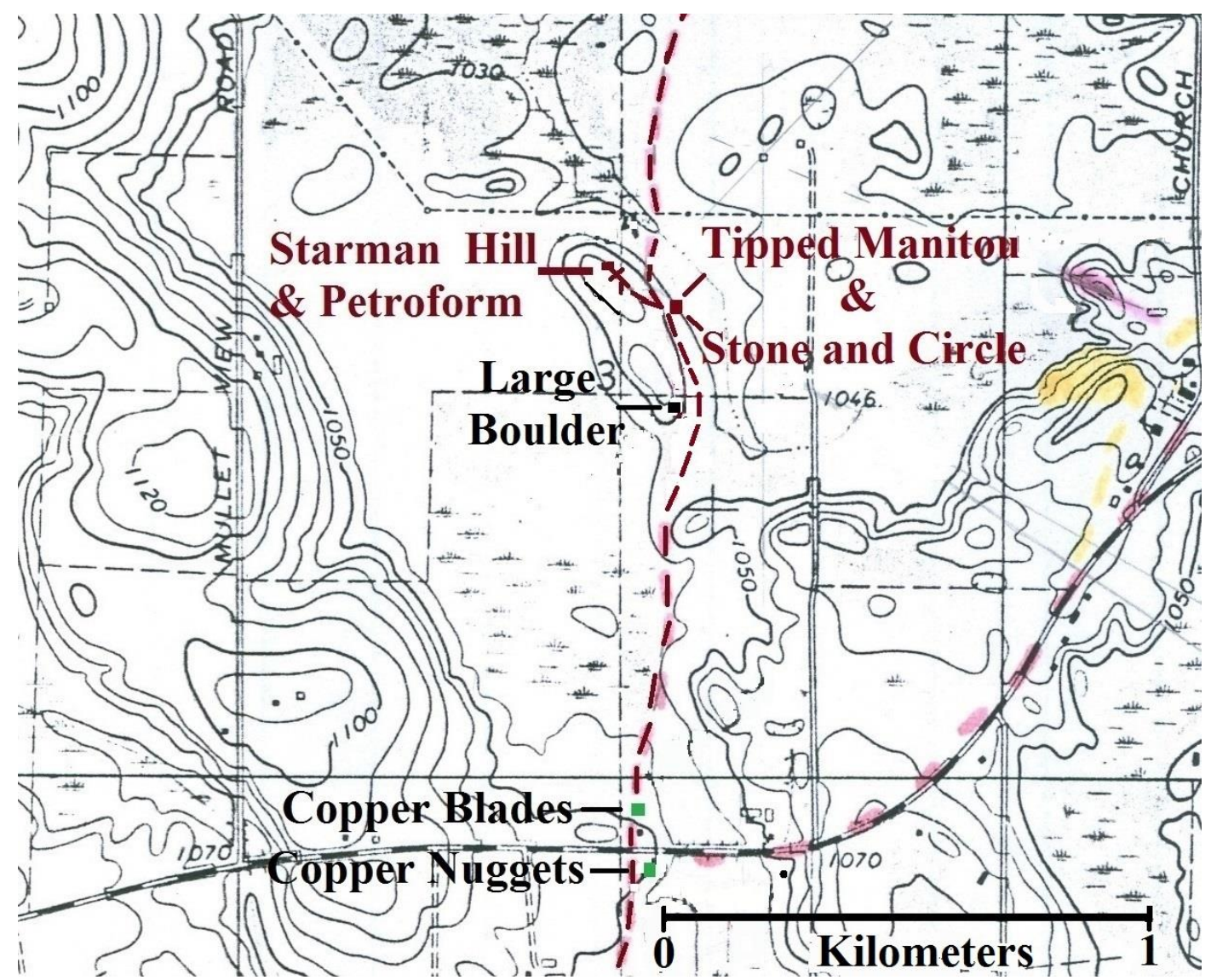

Figure 3. Portion of a United States Department of the Interior Geologic Survey, Dundee Quadrangle, Wisconsin, 7.5 Minute Series (Topographic) map showing the Starman hill, trail (dashed line), tipped Manitou stone and where refined copper nuggets and a copper blade were found. Contour lines are at 10 foot intervals.

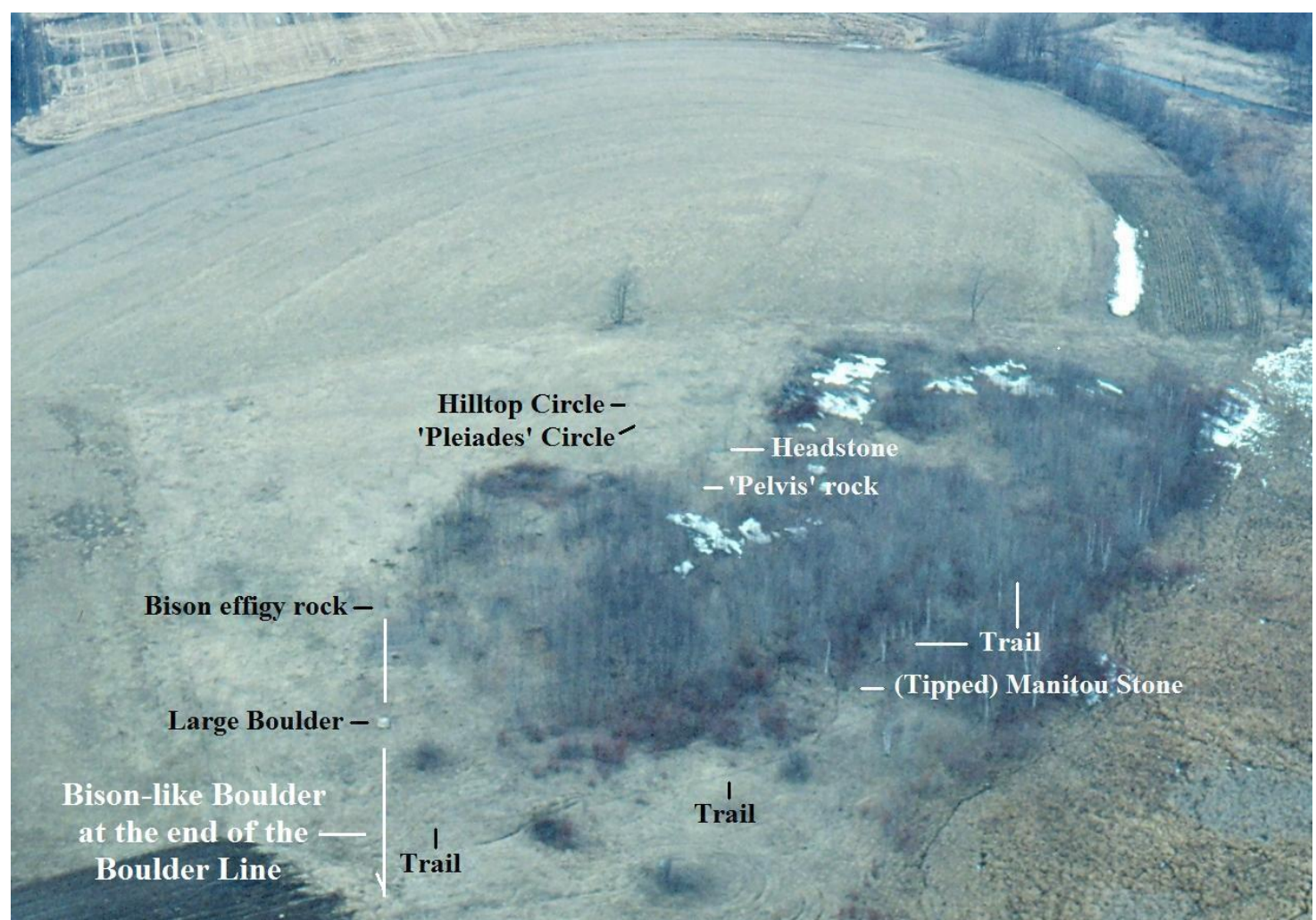

Figure 4. Aerial photograph of the Starman hill with the hilltop circle, the 'Pleiades' circle, the Starman headstone, pelvis rocks and other site features identified (Figure 2). View is looking approximate north. 


\subsection{Description of principal stones}

On the morning of the first visit, I discovered what appeared to be a vestige of the trail and, looking north, saw a large boulder near the edge of a plowed field on the south slope of the 'target' hill (Figures 3, 4 and 5).

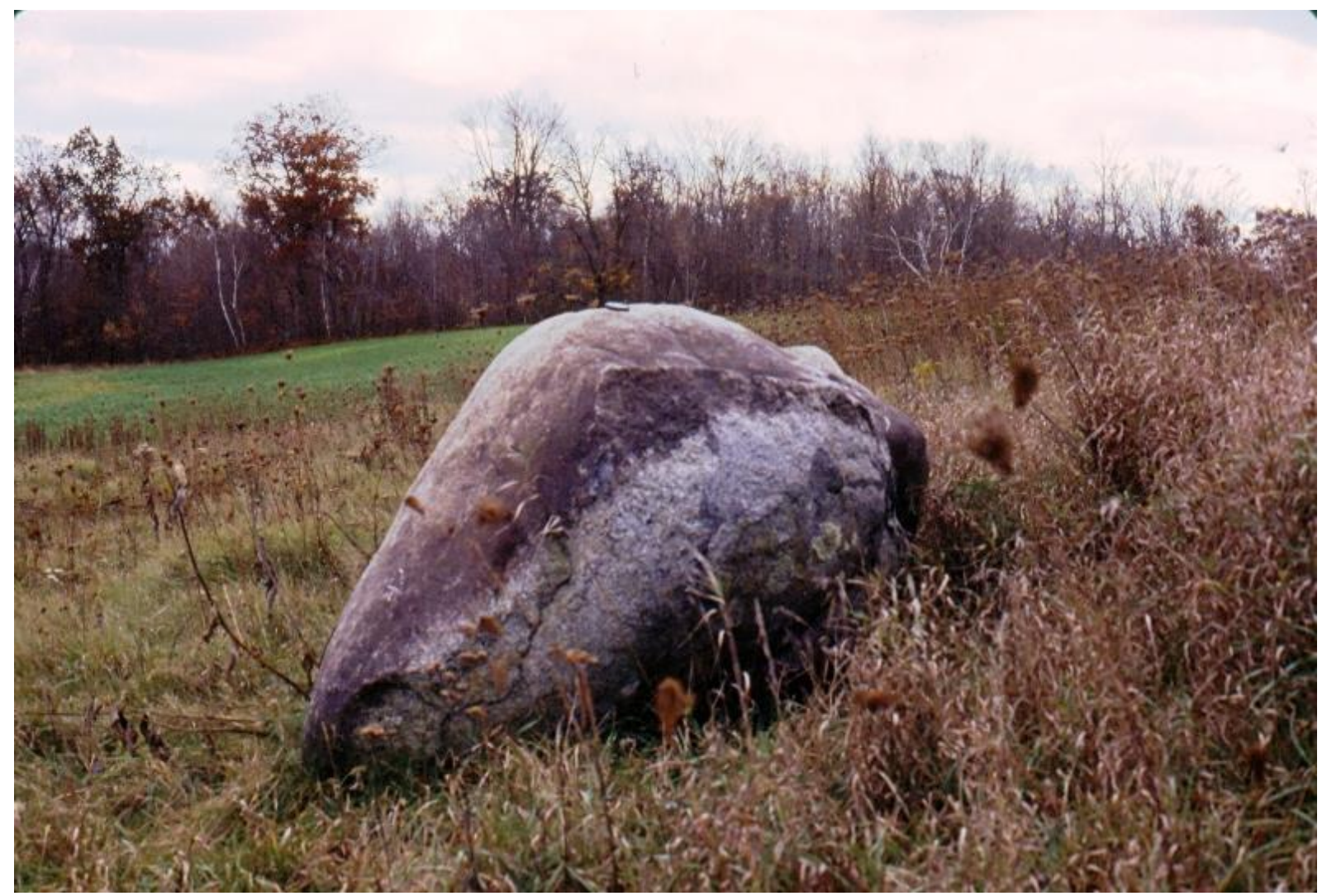

Figure 5. The large granite boulder, a glacial erratic resting on the southern end of the 'target' hill. It has been rolled out of place, the pit where it rested for millennia to the immediate west of the boulder. The highly weathered top is now at the bottom. View in photograph is looking west.

Once at the base of the 'target' hill slope, the trail was easily noticeable as a concave depression again running north between the hill's east slope and the broad marsh to the east (Figures 3 and 4). This trail was almost certainly the one the local inhabitants and farmers had informed me was there. It had been used by cows at one time, the rut produced by the cows within the edges of the wider trail. Following the trail north a bit farther, my pace quickened when I saw a large, red-rhyolite boulder lying on its side just ahead (north) of me (Figures 3, 4 and 6). The boulder, triangular in shape and about a meter high, was obviously tipped over and lying where it had once likely stood for millennia on what appeared to be an earthen mound surrounded by a circle of smaller boulders (Figure 6 and 7).

Here, by a spring opposite the now tipped standing stone, the trail split with a spur running up the hill's east slope. Following the trail and nearing the top of the hill, two prominent rocks were seen sticking up out of the grass. The largest rocks on the Starman site hilltop, both are bison-effigy rocks that were incorporated into the lithic outline of the Starman and aligned to face the summer solstice sunrise (Figures 2, 8, 9 and 10). Of glacial origin, they are highly weathered and deeply embedded in the soil as is the reddish-cast rock that was strategically placed to represent the red star Aldebaran (Figures 2 and 11). Aldebaran is one of the 20 brightest stars (0.87 visual magnitude), a K5III-M2V Class red giant (Abel 1984: A.38). 


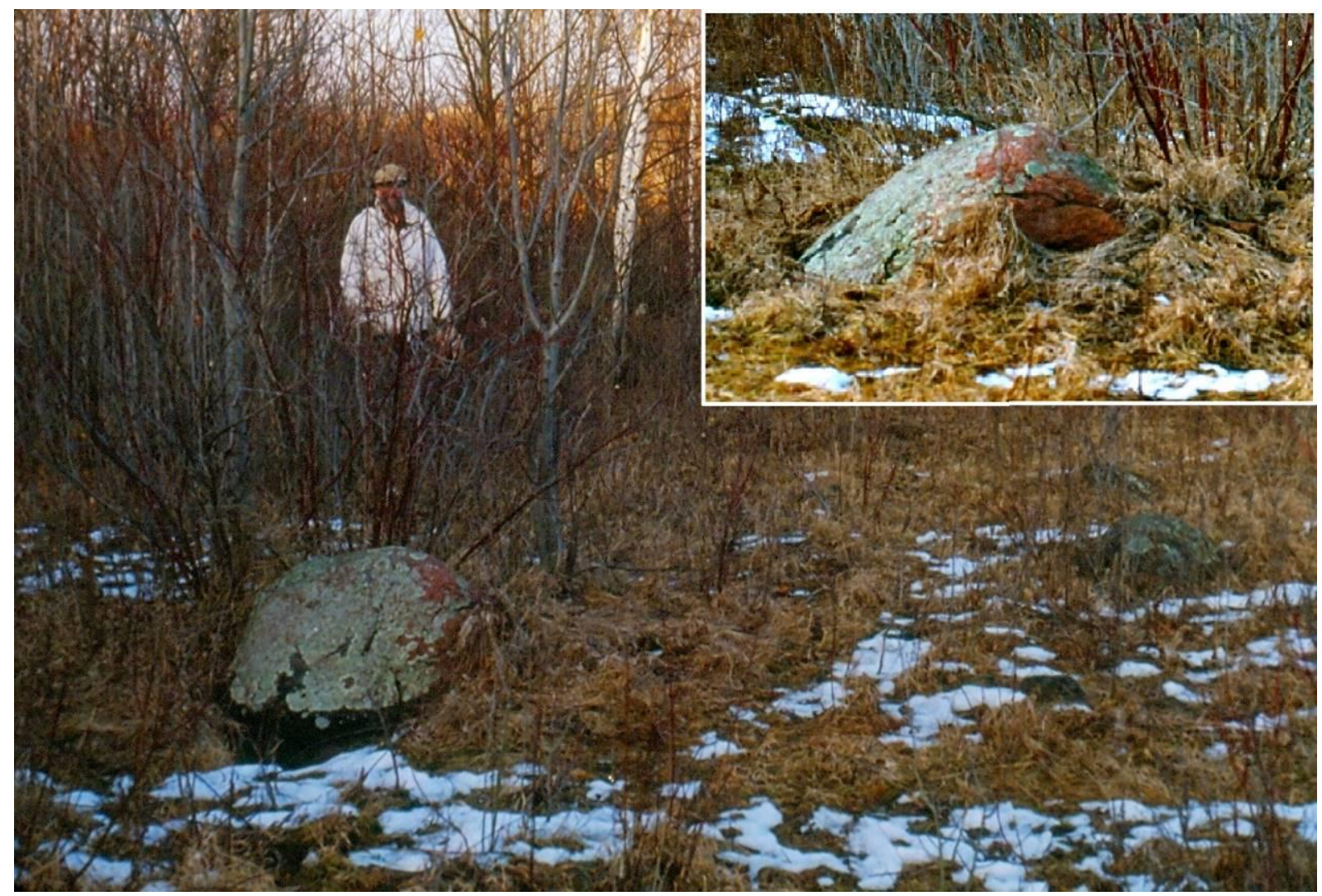

Figure 6. The metre or waist high, triangular-shaped, red rhyolite porphyry rock (now tipped) which once stood on an earthen mound surrounded by a circle of rocks partially visible in the photo.

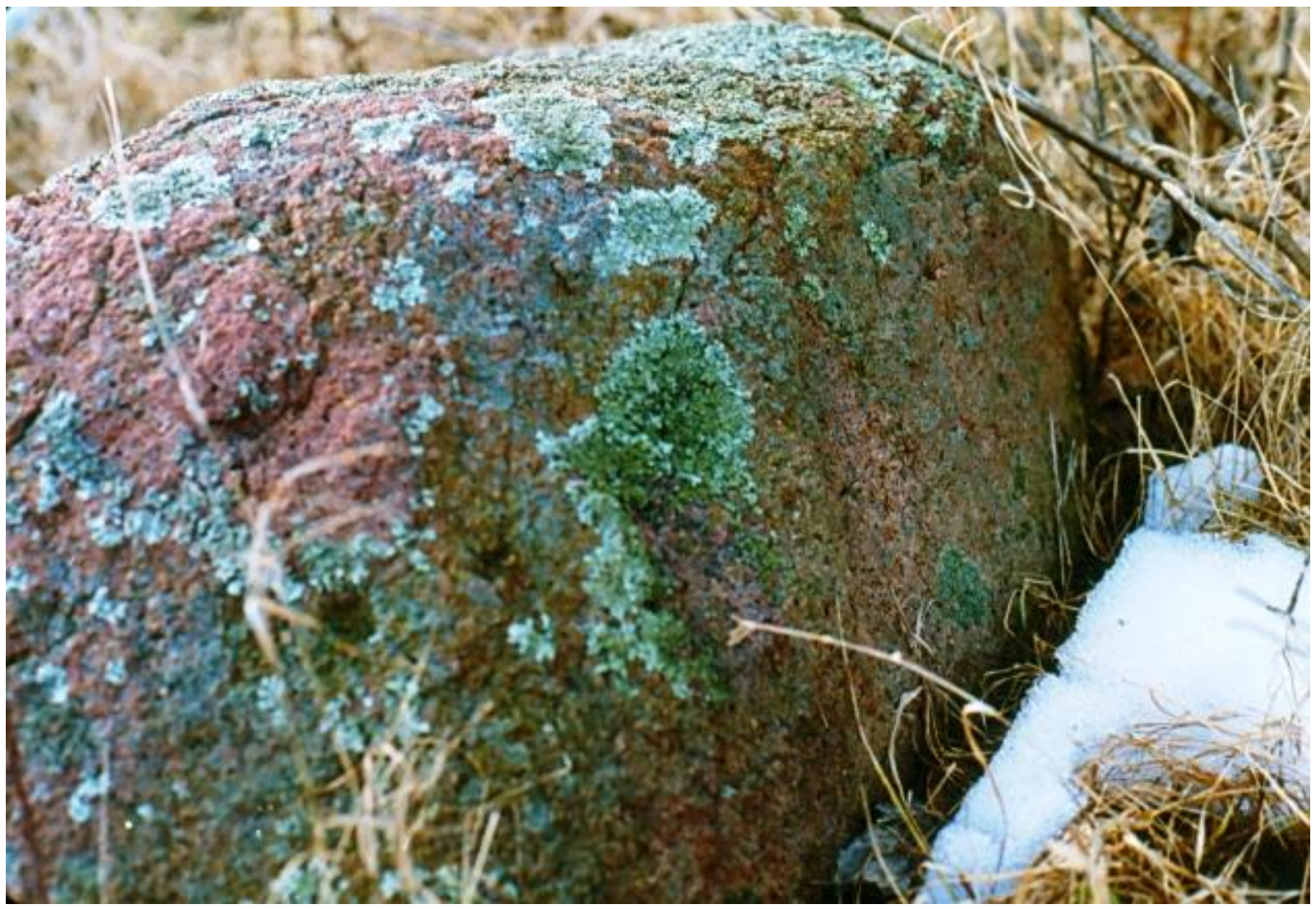

Figure 7. Photo showing the remarkable difference between the still smooth, flat base and highly weathered sides which, unlike the base, have been exposed to the long term weathering in the atmosphere. 


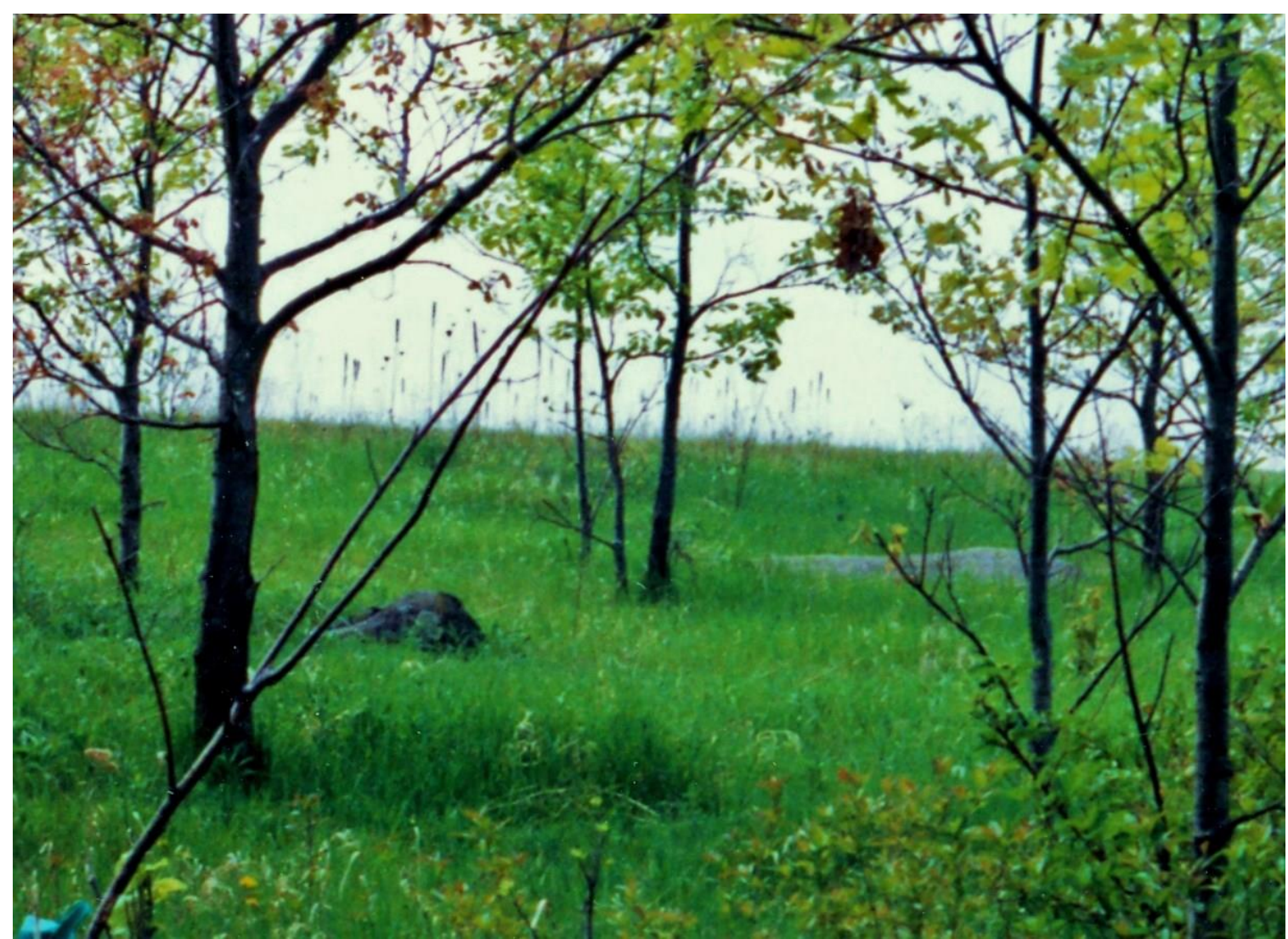

Figure 8. Photograph of the Starman petroform bison-shaped 'pelvis' rock (at left) and headstone (at right) in the tall grass (see Figures 2 and 4). View is looking approximately north.

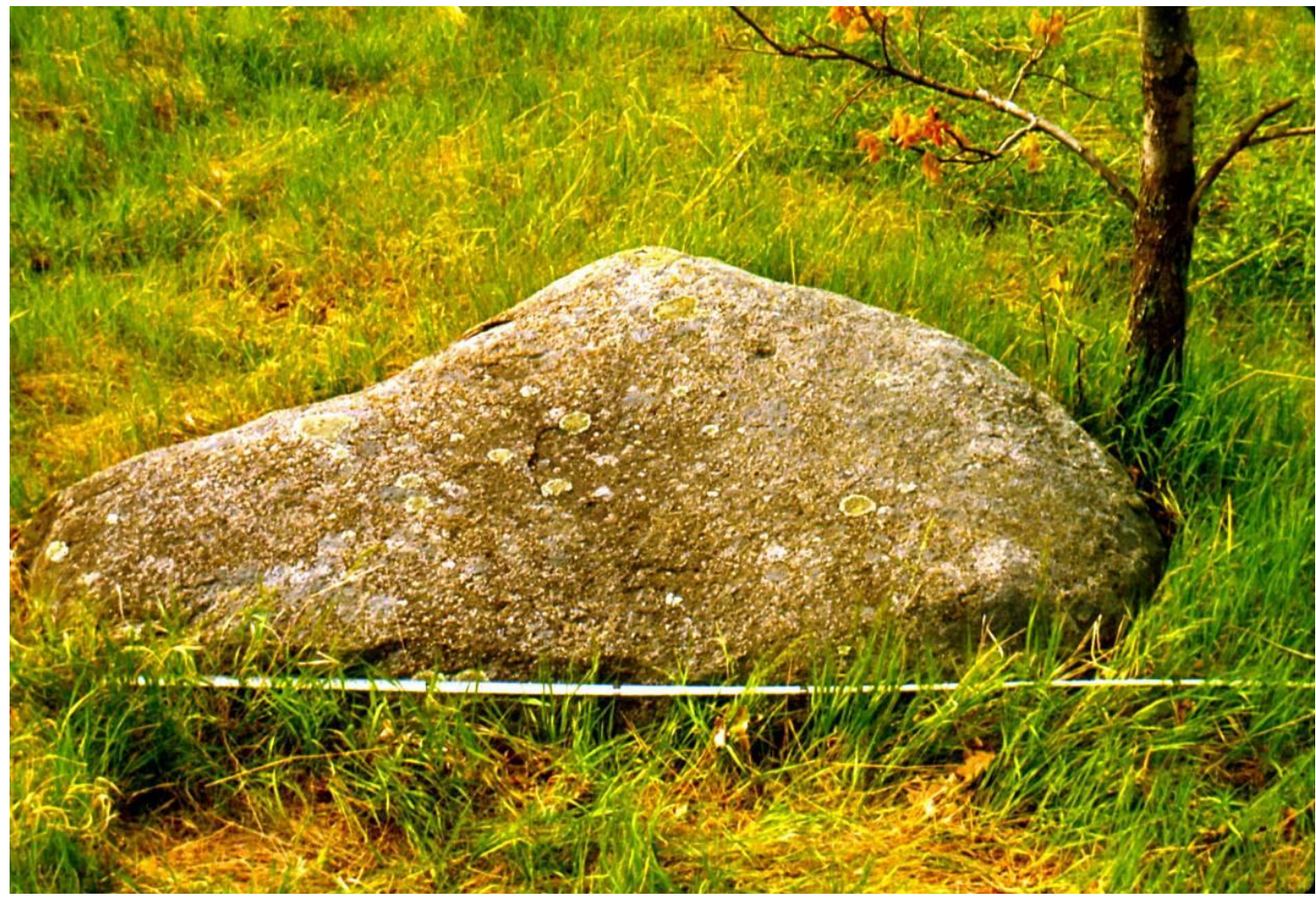

Figure 9. The Starman bison-shaped headstone aligned to face the summer solstice sunrise (see Figure 2). It has been worked to achieve the bison profile including the hump, head and straight, flat back end (Figure 2). It is over $2 \mathrm{~m}$ long and $1.7 \mathrm{~m}$ high to the tip of the hump. Extremely weathered red granite, the rock would have been bright red in colour when first positioned. 


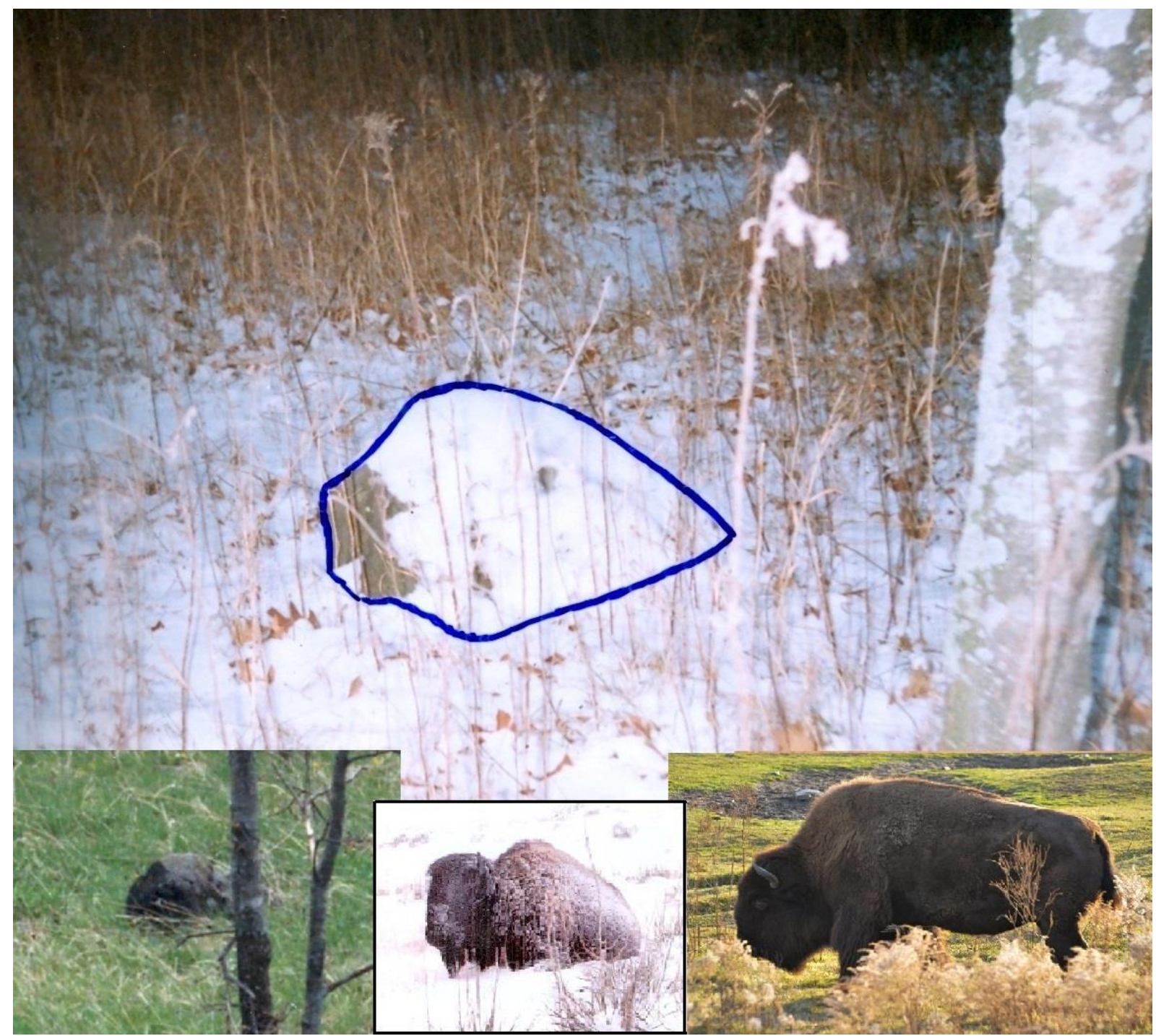

Figure 10. The Starman 'pelvis' rock covered in snow and in the tall grass (photo inset at lower left). It is a recumbent bison (photo inset bottom center) effigy aligned to face the summer solstice sunrise (Figure 2). Note the pronounced hump, flat face and head down posture reminiscent of a real bison (photo inset at lower right). It is almost a metre long. View is looking southeast.

Not a part of the Starman petroform, one other prominent bison effigy rock rests slightly below the south side of the hill summit (Figure 4). Facing east, it has been worked, the hump enhanced by pecking a circular base and the rear or back end squared off like that of a real bison in profile. At one time it likely had facial features, but if pecked, the process may have weakened the rock as the head is now exfoliated (Figure 12). An intermittent spring flows a slight distant to the west of the rock.

Located on the south-east hill slope, the largest boulder on the site (Figures 4 and 5) was utilized as the terminal point of an alignment of spaced rocks over which the winter solstice sunrise was observed from the hilltop circle (Figures 13 and 14). As mentioned, this rock was rolled and now rests on its highly weathered top next to (east) of the pit where it had originally rested. 


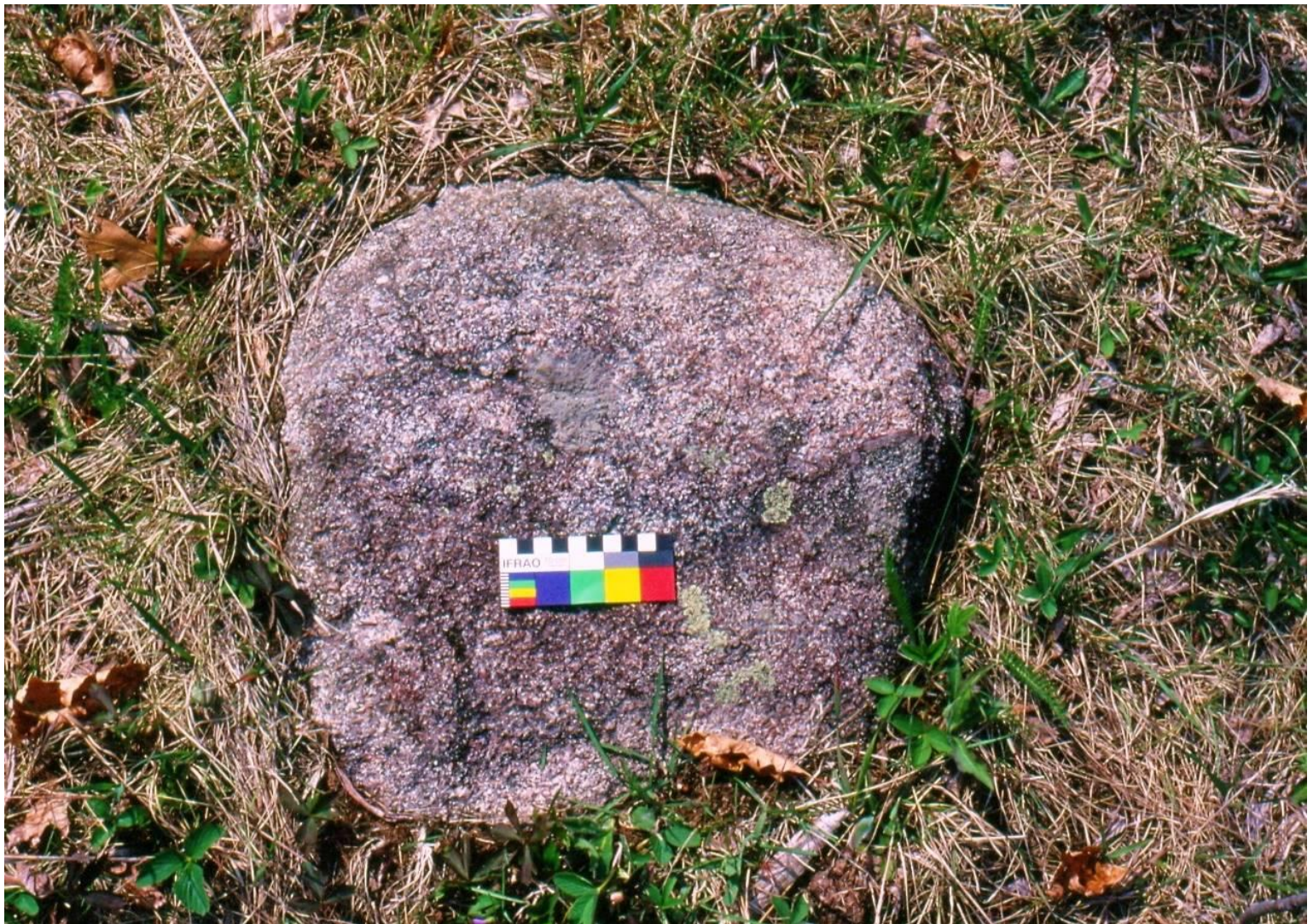

Figure 11. Photo of the extremely weathered and deeply embedded, reddish cast (granodiorite) rock placed to represent the bright, red star Aldebaran (Figure 2).

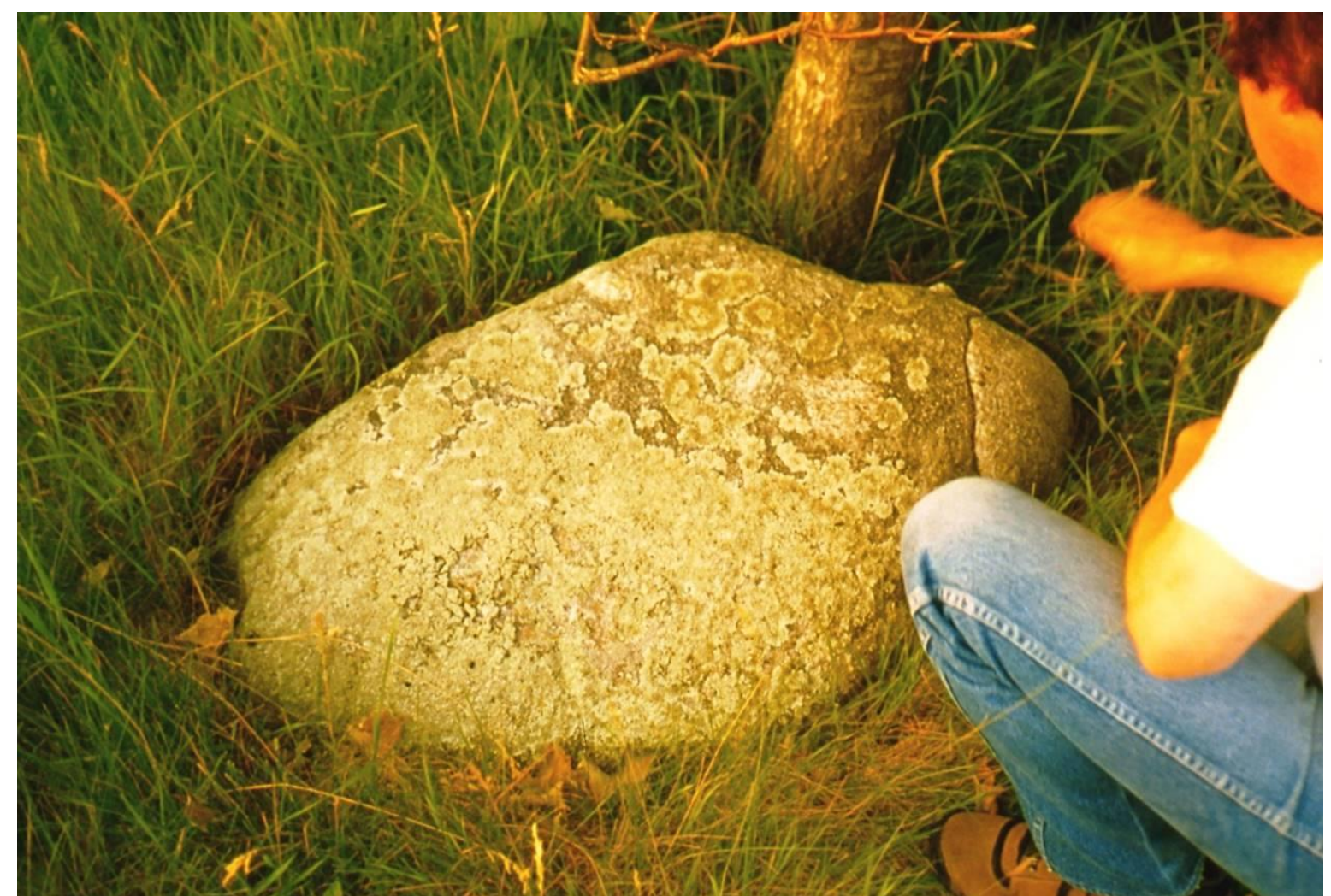

Figure 12. East-facing bison effigy rock on the south end of the hill summit (see Figures 2 and 4). The pronounced hump was enhanced by pecking about its base. The slight knob on the right or top of the head may have represented the horns in profile. The face portion of the rock is now exfoliated, a consequence of time and exposure to the elements. 


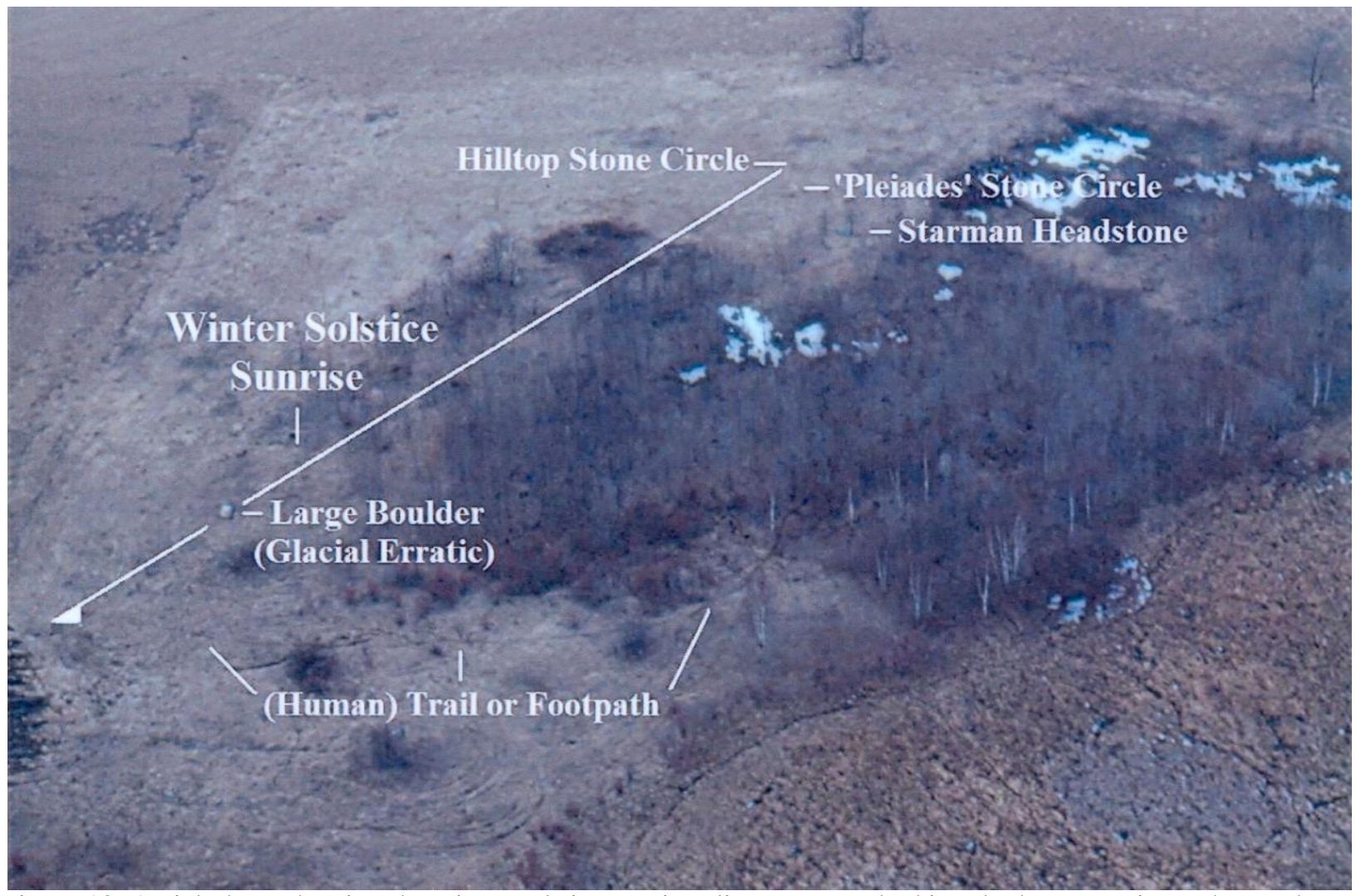

Figure 13. Aerial photo showing the winter solstice sunrise alignment overlooking the large erratic on the south end of the hill. The hilltop and Pleiades circles and Starman headstone locations are also indicated.

\subsection{Dating the Starman}

Dating sites like the Starman in an archeological context can be difficult. When excavated, petroform sites proper almost universally lacked any dateable artefacts or other cultural debris (Buchner 1980; Garvie 1991; Kehoe 1965: 15; Steinbring 1970a: 238, Steinbring \& Steinbring 1999: 10). They were, archaeologically speaking, non-productive and therefore problematic, i.e. not really conducive to accepted archaeological excavation methodology, paradigms or peer review looking for artefact data only. However, at the Starman site, four indirect dating methods were eventually employed. All indicated the same time period indicating a 'best fit' date of epoch 1500 BCE.

One of the dating methods, the observed degree of the shift of the obliquity of the ecliptic (Aveni 1972; Meeus 1991: 135-136) was anticipated and then confirmed by observation and photographically (Figures 15 and 16). A second dating method, the apparent degree of stellar precession of the equinoxes (Gribbin 1996: 322-323; Meeus 1991: 123-130), i.e. the apparent shift of stellar rise azimuths over time for the proposed individual star rise alignments, is based on the azimuths of spaced rock alignments and heliacal star rises for the epoch (Figure 17 and Table 1).

At the Starman site, the epoch of probable use had been determined by the realization that the lone red rock placed in the 'foot' of the petroform unambiguously correlated to the red star Aldebaran in the Hyades (Figures 2 and 17) and the degree of shift in its rise azimuth over the millennia (Bender 1994a). It was a most critical step in the site investigation. Over the next two years using an off-the-shelf precession program (Sky Map 1.3), the spaced rock alignments were consistently seen to align with the center of a one degree high by one and half degree wide 'target box' approximately two degrees above the horizon for the helical rise of eight separate bright stars and the Pleiades 3500 years ago (Figure 17). 


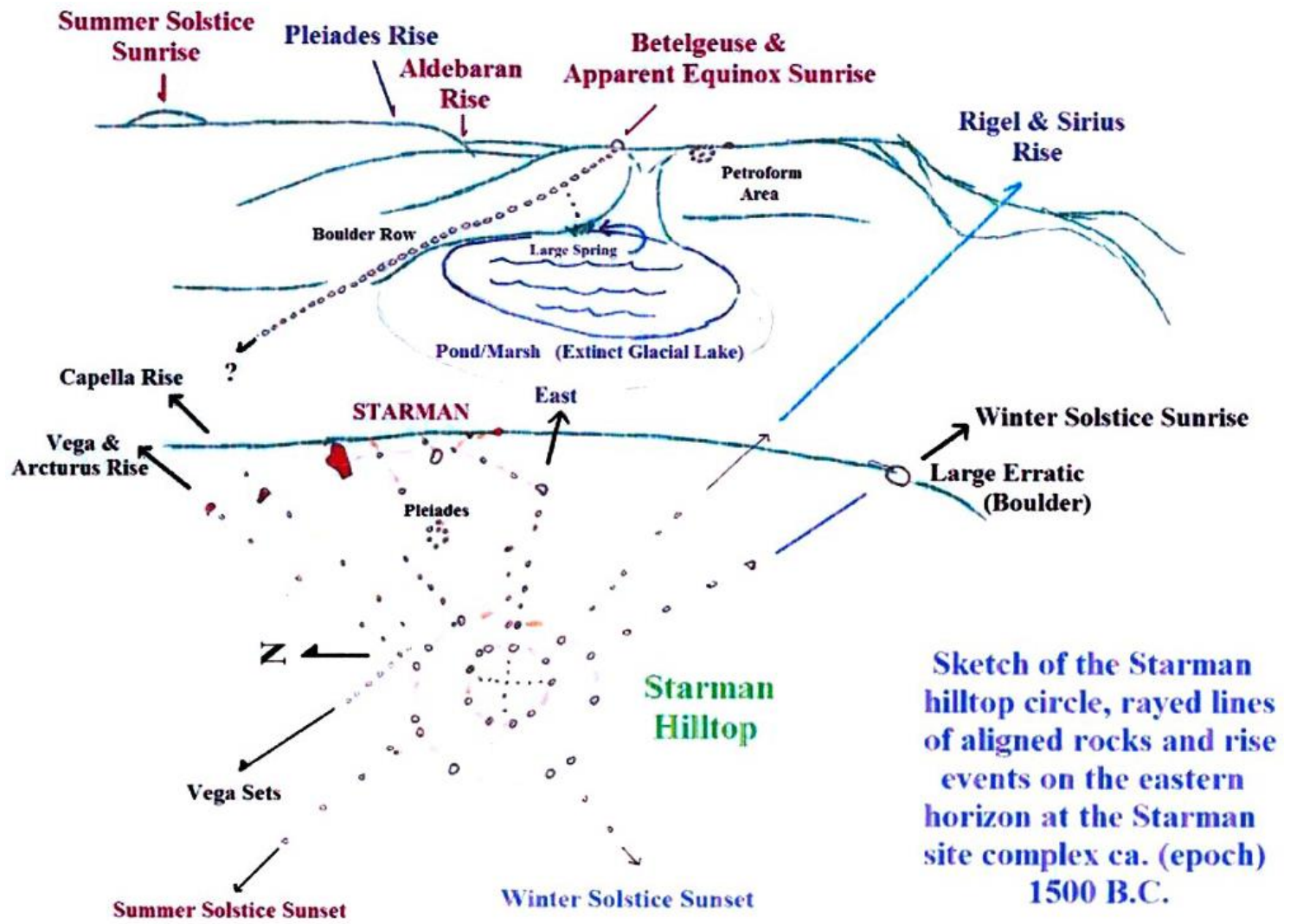

Figure 14. Sketch map of the Starman site showing the cross-in-circle hilltop circle and alignments of spaced rocks radiating toward the eastern horizon where star and solstice sunrises and sunsets were observed. Note also the large erratic boulder on the winter solstice sunrise alignment or azimuth (Figure 13). According to long term land owners whose properties have been in the same families for generations, cairns were located on distant hilltops in-line with the proposed stellar alignments before being destroyed by post-World War 2 agricultural land clearing.

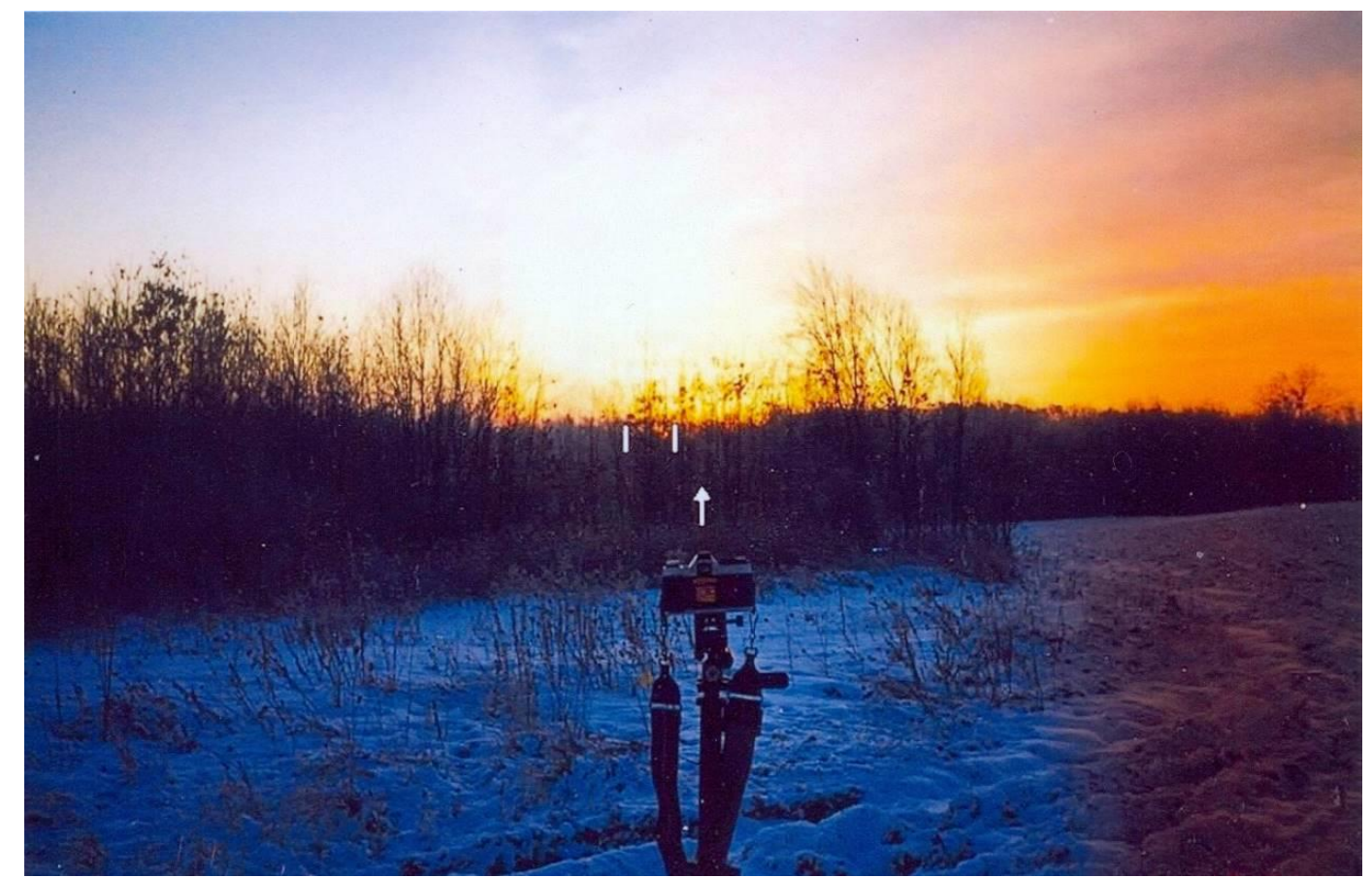

Figure 15. The winter solstice sunrise (full disk between the parallel vertical white lines) viewed from the hilltop circle. Note that the disk of the sun shifted a minimum of one full sun disk north (left) of the camera centre (and arrow) pointed along the alignment of spaced rocks and toward the large boulder (Figures 13 and 14). The effect is due to the shift of the obliquity of the ecliptic or change in the earth's tilt over 3500-5000 years. 


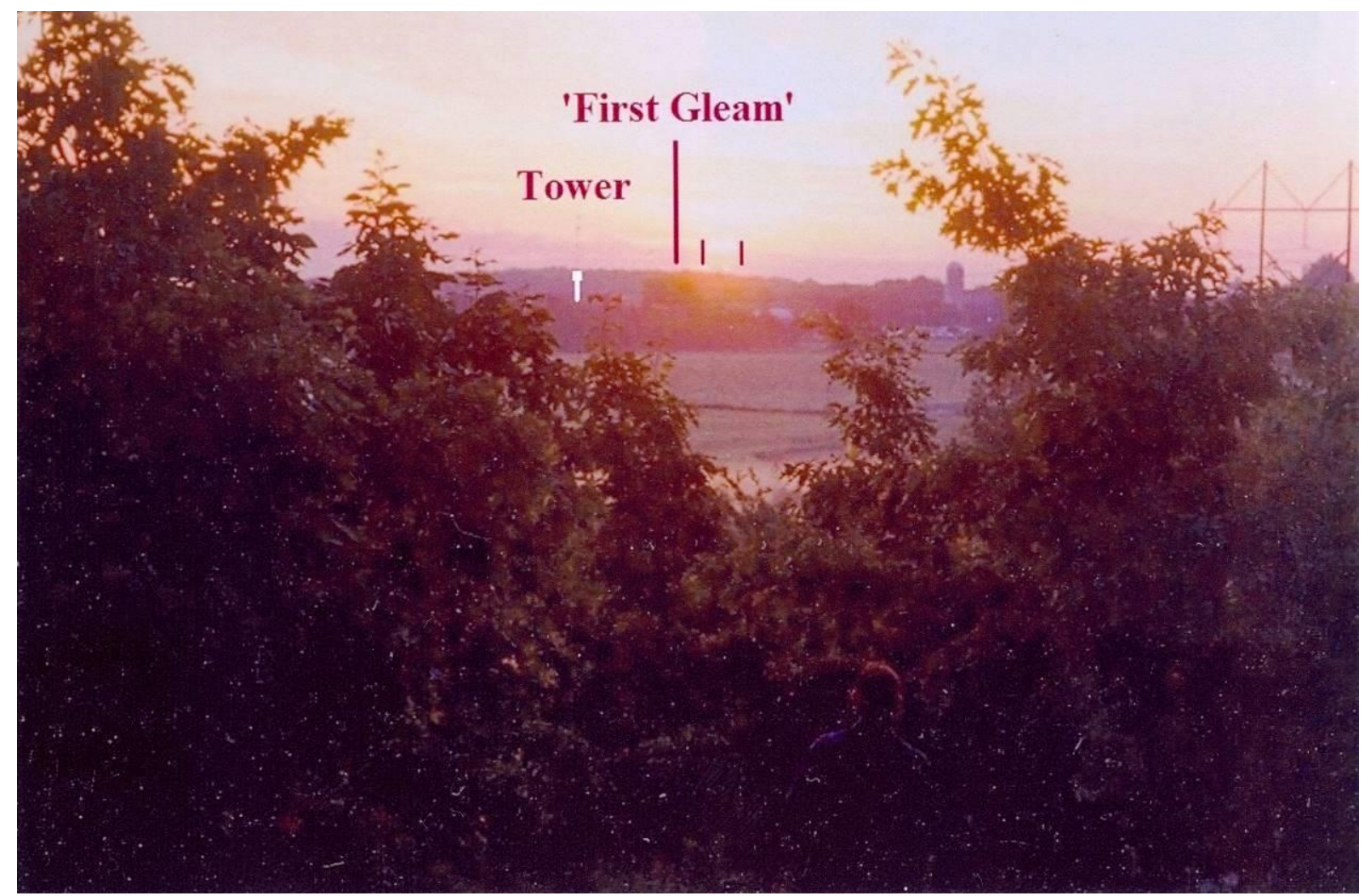

Figure 16. Photograph of the summer solstice sunrise viewed from the Starman site hilltop circle. Note the sun (between the two parallel vertical lines) and its extreme shift south (right) of the centre of the hill marked by a tower and white line. Three parallel summer solstice alignments at the Starman site point at the direct centre of the hill which is approximately $3 \mathrm{~km}$ distant across the marsh (Figures 2 and 7).

Table 1: Stellar rise azimuths about $1500 \mathrm{BCE}$ at $43.75^{\circ} \mathrm{N}$. latitude. (Rise azimuths calculated at approximately $1.5-2.5^{\circ}$ elevation unless noted). Current and precession stellar rise values calculated from SkyMap Pro Version 8 (Marriott 2001).

\begin{tabular}{lcc}
\hline & \multicolumn{2}{c}{ Azimuths } \\
\hline Eegach 1500 BCE & Epoch 2000 CE \\
Vega & $\sim 29^{\circ}$ & $\sim 32^{\circ}$ \\
Arcturus & $\sim 32^{\circ}\left(\right.$ elevation $\left.3^{\circ}+\right)$ & Vega -- little changed over the epochs \\
& $\sim 30^{\circ}$ & $\sim 64.5^{\circ}$ \\
Deneb & $\sim 33^{\circ}\left(\right.$ elevation $\left.3^{\circ}+\right)$ & \\
Capella & $\sim 35^{\circ}(+)$ & $\sim 15^{\circ}$ \\
Castor & $\sim 41^{\circ}$ & $\sim 12^{\circ}$ \\
Pollux & $\sim 47^{\circ}$ & $\sim 45^{\circ}$ \\
Pleiades & $\sim 51^{\circ}$ & $\sim 51^{\circ}$ \\
Procyon & $\sim 81^{\circ}$ & $\sim 57^{\circ}$ \\
Aldebaran & $\sim 81.5^{\circ}$ & $\sim 84^{\circ}$ \\
Betelgeuse & $\sim 86^{\circ}$ & $\sim 68^{\circ}$ \\
Sirius & $\sim 91^{\circ}$ & $\sim 81^{\circ}$ \\
Rigel & $\sim 117^{\circ}(+)$ & $\sim 116^{\circ}$ \\
\hline
\end{tabular}




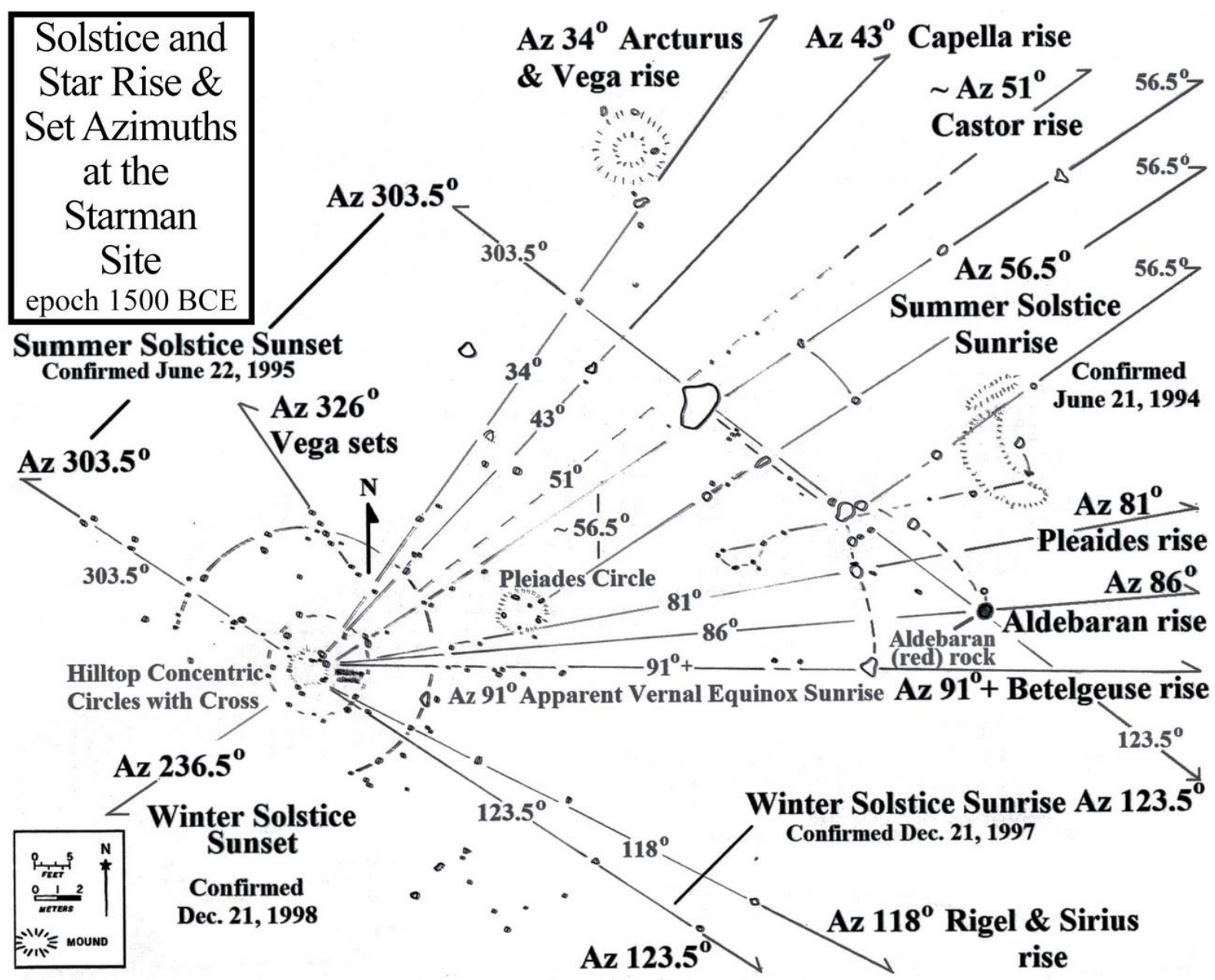

Figure 17. Map of the Starman site showing all the rocks mapped on the site (see Figures 2 and 14) together with the alignments of spaced rock identified for the solstice rise and set azimuths and the stellar heliacal rise azimuths observed from the hilltop circle ca. $1500 \mathrm{BCE}$.

A third method of dating the time of prehistoric habitation when the Starman site was likely laid out and utilized is through examination of the proximal area land owners' artifacts collected over the past hundred and seventy years. A comprehensive analysis of artifact collections gathered by area landowners was conducted early in the investigation. Dated by their style, shape and workmanship (Figure 18), artifacts in all the collections that were examined are overwhelmingly pre-ceramic in date or age dating from the middle to late Archaic period circa 3000-1500 BCE (Goldstein \& Osborn 1988; Stoltman 1986).

Collections included two distinctive and diagnostic Old Copper Culture tanged-base spear points (Figure 18) approximately 4000 years old (Steinbring 1997; Stoltman 1986: 217226).

Rock art studies were also employed. By examining the Archaic age petroglyphs at the Jeffers Petroglyph Site on the Minnesota-South Dakota border (Lothson 1976; Steinbring 1999), temporal and stylistic links were established through comparison to the pecked images of bison, tanged copper spear points, and stickman figures bearing atlatls in a pose identical to the Starman (Figure 20). Some atlatl symbols at Jeffers and that of the loop-handled atlatl bearing Starman are a close match with similar symbols found at Indian Knoll in Kentucky which have been dated to 3000-1000 BCE (Lothson 1976: 29-30; Callahan 2004: 60, 63), dates coeval with the proposed date for the Starman petroform. 


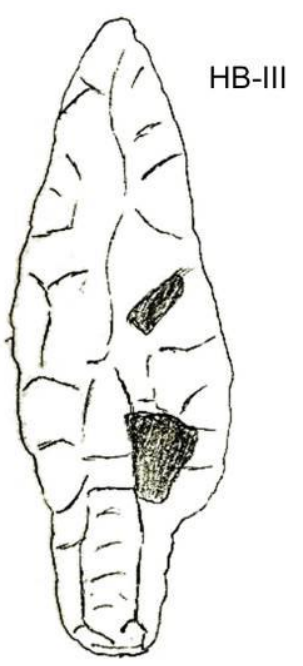

Silurian

Chert

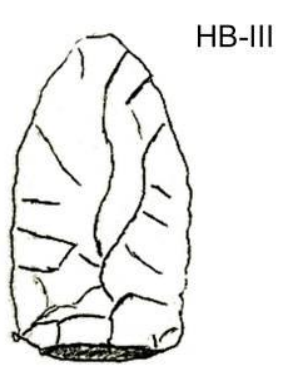

Galena Chert

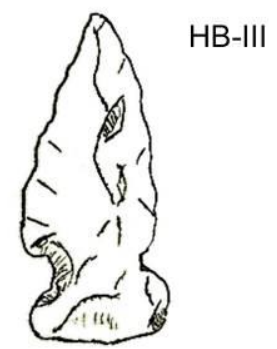

Silurian Chert

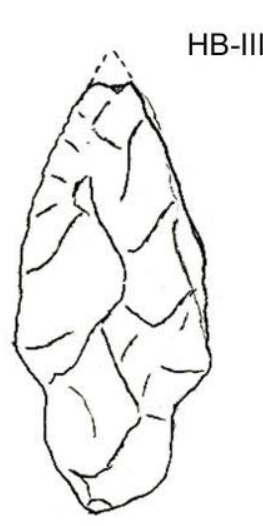

Silurian Chert

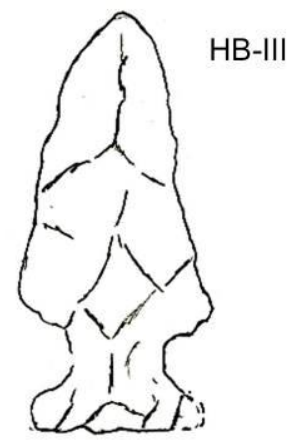

Silurian Chert

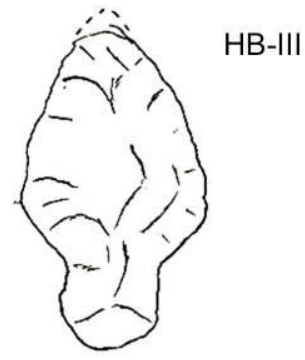

Milky Quartz

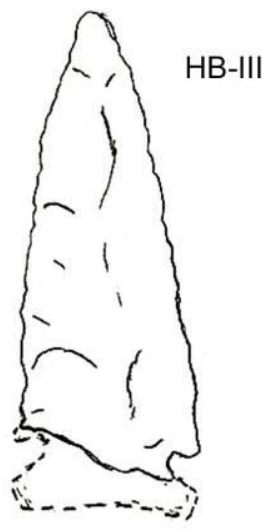

Prairie du Chien Chert (Shakopee Frm.)

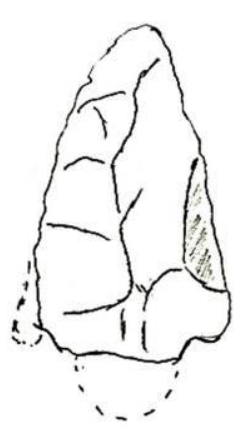

Silurian Chert

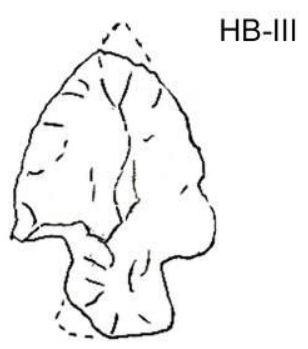

Galena Chert

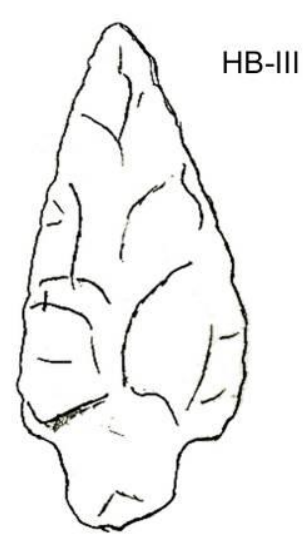

Prairie du Chien Chert (Oneonta Frm.)

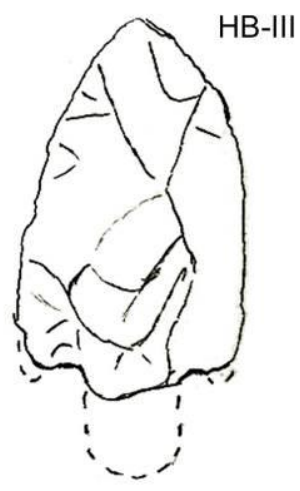

Silurian Chert

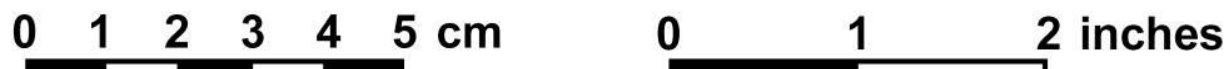

Figure 18. Sketches of artefacts from an area land owner's personal collection of lithic points found approximately 1.5 kilometers north of the Starman site. All are mid to late Archaic period in age (3000-1000 BCE) and made from cherts typical to southeastern Wisconsin. Well over 200 points from two private collections were examined with over 95\% dating pre-1500 BCE.

Another clue to the age at Jeffers comes from the projectile point carvings which show numerous 'rat-tailed' stemmed and tanged projectile points (Lothson 1976: 17, 25, 45). The only material in use at the time malleable enough to produce long, thin-tailed points is copper (Figure 19), and indicates Old Copper Culture age technology serving as another horizon marker for the late Archaic period date of the Starman petroform site (Lothson 1976: 31; 
Steinbring 1970b: 61). This is also consistent with the date and arc of copper point distribution spread west and north from southeastern Wisconsin to the grasslands of Manitoba in lower Canada (Steinbring 1970b: 69). Of interest, bison hunting scenes using atlatls abound at Jeffers, perhaps not unexpected, and bison effigy rocks also occur as a part of the cultural landscape associated with the geographic arc and time line (Bender 2013).
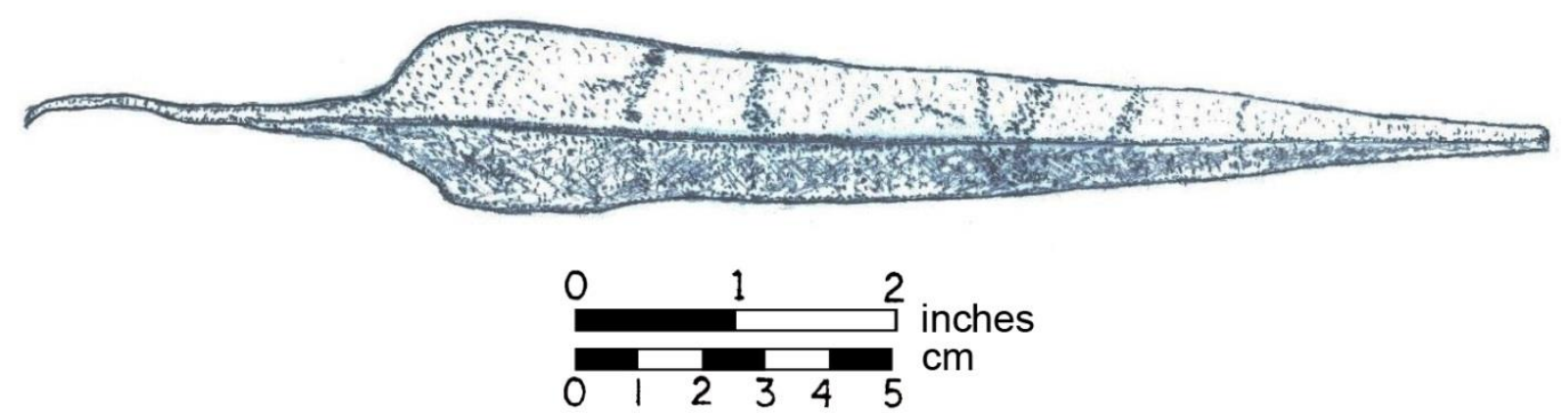

Figure 19. Field sketch of Old Copper Culture tanged or 'rat-tail' spear point found on the trail directly south of the Starman site where refined copper nuggets were also recovered (see Figure 3). Another almost identical spear point was found there in the 1930's or earlier. The large size (approximately $30 \mathrm{~cm}$ ) indicates a purely ceremonial use. A number of other rat-tail and tanged-base Old Copper Culture spear points were found just to the east and south of the Starman site area (Steinbring et al 1995, Steinbring 1997).
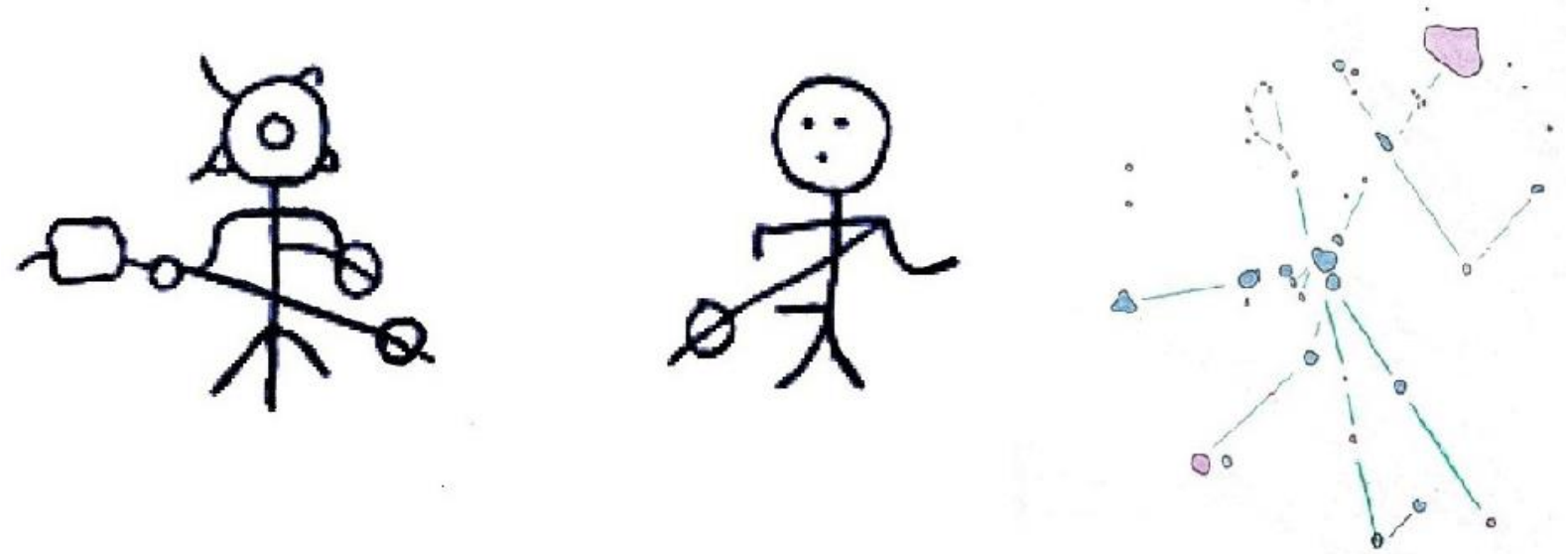

Figure 20. Petroglyphs of stickmen bearing atlatls with an erection at the Jeffers Petroglyph site in the same pose as the Starman petroform (at right) with a massive erection and bearing a loop-handled atlatl. The pecked image at left is approximately $0.8 \mathrm{~m}$ long, the middle figure approximately $0.5 \mathrm{~m}$.

\subsection{Cheyenne cosmology, stars and the Wolves of Heaven}

The indigenous purpose for creating petroform sites like the Starman is difficult to ascertain. A major reason for the uncertainty is the difference between a function, i.e. how the site is physically connected to the landscape and sometimes the sky, versus the purpose of why it was constructed and how it functioned in a spiritual sense (Bender 2008b). At the Starman site, the discovery of solstice alignments and then a later revelation of stellar alignments keyed to the landscape could be confirmed by careful mapping and computer driven astronomical precession programs. These alignments represented site function, i.e. a physical if not tangible connection to the landscape and sky interface, but could not explain the purpose of why they were established. This was to change in the summer of 1995 after an article published in a local newspaper about the preliminary Starman site investigation came to the attention of representatives of visiting Cheyenne Indian Nation delegation.

Within a month, a traditional Northern Cheyenne elder and healer and member, Mr. Ralph Redfox of Boise, Idaho, contacted me and asked for permission to visit the site in 
September. Upon meeting for the first time, rather than inquiring about the possibility of visiting the site, he explained that he came "seeking centre." He instead asked if I had the "sunrise on the longest day" or the summer solstice sunrise and "certain stars" at the Starman. The stars Mr. Redfox asked about were the Pleiades, the "red wolf named Aldebaran", the "white wolf" the "blue kit fox [star]" and the "black star in the northeast," later in the conversation identified as Vega. The "white wolf" and "blue kit fox" stars were still unnamed. It had already been determined that the lone red rock in the Starman petroform represented the red-star Aldebaran in the Hyades (Bender 1994a: fig. 2). In addition, the summer solstice sunrise alignment had already been verified (Figures 2, 16 and 17). Furthermore, rocks placed to represent the Pleiades had been mapped along with alignments of spaced stone that we would shortly learn indicated the azimuths for the heliacal rise slightly above the horizon of Aldebaran, the Pleiades, Capella, Vega and Betelgeuse. Utilizing a computer precession program, the azimuths for all of them indicated that they were likely observed rising in the predawn sky ca. 1500 BCE (Bender 1994b; 1995).

After further communication from Mr. Redfox and members of the Cheyenne Wolf Lodge in March 1996, it became evident why he had asked about the "red wolf" Aldebaran, the "white wolf" that we call the star Sirius, and the "blue kit fox" [star], i.e. the blue-white star Rigel. Mr. Redfox had suggested we look at the most detailed description of the Massaum ceremony or "Crazy Animal Dance" described by Karl Schlesier (1987: 77-109) in the book of Cheyenne cosmology, The Wolves of Heaven. The Massaum, a world renewal ceremony and ritual bison hunt originated with the Cheyenne cultural hero Motseyoef, better known as Sweet Medicine (Grinnell 1972: 285-336; Hoebel 1960: 7, 16-17; Powell 1969: 26; Schlesier 1987: 78). Ancient by all accounts, Mails (1973: 26) stated that the rituals for the Massaum were given to the Cheyenne by Sweet Medicine in about 1000 BCE (a date which closely supports the corroborating astronomical, artefact and rock art dates).

The primary spirits or maiyun Sweet Medicine and a companion met in the Wolf Lodge where the Massaum ceremony originated were Nonoma and his wife Esceheman. Nonoma is "Thunder" and the "red wolf" represented by the red star Aldebaran (although in more ancient times, the red wolf star may have been Betelgeuse). Esceheman, "Our Grandmother", is the deep earth represented by the "white wolf" and bright star Sirius (Schlesier 1987: 8, 15, 84). Nonoma and Esceheman had a daughter, Ehyophstah or "Yellow-haired woman" who is a buffalo spirit in human form and was given as wife to the companion of Sweet Medicine (Schlesier 1987: 78). This giving was the origin of the Massaum, the Cheyenne renewal ceremony which is a giving of the earth in all four directions and the establishing of a sacred relationship with animals (Schlesier 1987: 78). Ehyophstah represented Voh'kis the 'blue kit fox' in the Massaum (Schlesier 1987: 84), known to us as the blue-white star Rigel.

To the Tsistsistas as the Cheyenne call themselves, the Massaum consisted of 56 days and incorporated the anticipated heliacal rise of the bright stars Aldebaran, Rigel and Sirius on timed, 28-day intervals beginning on the summer solstice (Schlesier 1987: 83-84). The incremental 28-day timing of events was a core element of the Massaum (Hoebel 1960: 1617). The number 28 is a significant and sacred number to most Plains Indian groups, the number of ribs in a bison, days "the moon lives" and a woman's menses (Powers 1977: 5051). It is the product of two other sacred numbers, four and seven (Kehoe 1992: 212, Nabokov 1967: 24, 27; Powers 1997: 4). Schlesier (1987: 87, 91) sees the Big Horn Medicine Wheel with its 28 spokes as a flattened version of a Massaum wolf lodge built on a 28 pole frame.

After learning of the "white wolf" and "blue kit fox" and keeping their function in mind, the shared alignment used to anticipate the heliacal rise for both Sirius and Rigel was discovered at the $118^{\circ}$ azimuth where the precession program indicated it would have been ca. 1500 BCE (Bender 1996). By 1998 the Starman site mapping of all solstice and stellar 
alignments for epoch 1500 BCE was complete with all of the rocks, no matter how small, mapped (Figure 17, Table 1). Using the stellar precession program and looking only at first magnitude or brighter stars important in Plains Indian cosmologies, the sequential timing for heliacal star rise azimuths that would have occurred on approximate 28 day intervals before and after the summer solstice, observed in-line with the alignments of spaced rocks, was completed (Figure 17).

At the Starman site, the 'best fit' timing strongly suggests that the stellar incremental day count leading up to the Massaum began approximately 84 days (28 days X 3) before the summer solstice (sunrise) with the heliacal rise of Capella. It was then followed by the Pleiades which rose at the half-way point 42 days later (28 days x 1.5). Aldebaran rose heliacally 14 days ( 28 days X 0.5 ) after the Pleiades. Then, 28 days later, Betelgeuse (the "red wolf" at the time) rose helically in the dawn sky the day of the summer solstice sunrise, signaling the start of the Massaum ceremony and ritual hunt. Rigel (the "blue kit fox") rose 28 days after the summer solstice sunrise followed 28 days later by Sirius (the "white wolf"), signaling the end of the ritual hunt. The 28-day intervals starting with heliacal rise of the red stars Aldebaran and Betelgeuse, the blue star Rigel and the white star Sirius timed before, one the day of and after the summer solstice are important not only for the number symbolism, but the color attributes preserved in the Cheyenne Massaum ceremony as the maiyuns. It would not be until a thousand years later and as a consequence of the precession of the equinoxes that the red star Aldebaran first rose heliacally with the summer solstice sunrise ca. 100-500 C.E. (Eddy 1974; 1977; Schlesier 1987: 85). It became the "red wolf" star of the Massaum, likely replacing Betelgeuse whose time had long passed.

Through knowledge of the ancient stories and ceremonies, the Starman lithic complex has gone beyond the determination of an astronomical function to, as the Cheyenne saw it, the original purpose for its construction. Utilizing the input from the Cheyenne and ancient Tsistsistas tradition, it is likely the first time that a petroform or megalith site's purpose may be linked to an ancient Plains Indian ceremony, one with a genesis or origin in the east whence the people migrated. Furthermore, its discovery had been anticipated by the Cheyenne becoming, according to Cheyenne elders, a fulfillment of prophecy to return to their origin.

\section{The Star-Being}

Discovering one giant human-like petroform, the Starman, determined to be a star map in the Native sense was unexpected, to say the least, and considered by some, if real, the "holy grail" in archaeoastronomy (personal communication with Ed Krupp, December, 1994). But to first discover and then identify a second star-based petroform, the Kolterman Star-Being, was fortuitous and lent credence if not credibility to both. As mentioned previously, a comprehensive description of the (Kolterman) Star-Being has already been published (Bender 2004). However, a review of its salient features together with more recent mappings of an additional petroform together with personal conjecture formed since then are not only timely, but considered appropriate. Furthermore, a report on features mapped at the Star-Being site since the 2004 publication was authored will help to define the cosmological significance of additional petroform and two bison-effigy stones that were likely utilized in conjunction with the Star-Being.

The Star-Being lithic outline or petroform is an approximate $20 \mathrm{~m}$ long, stickman-like lithic effigy with a serpentine body ending with up-turned 'tail', wing-like arms and a bisonshaped headstone. There is a partial diamond-shape or obtuse triangle of stones shaped above the Star-Being headstone (Figure 21). 


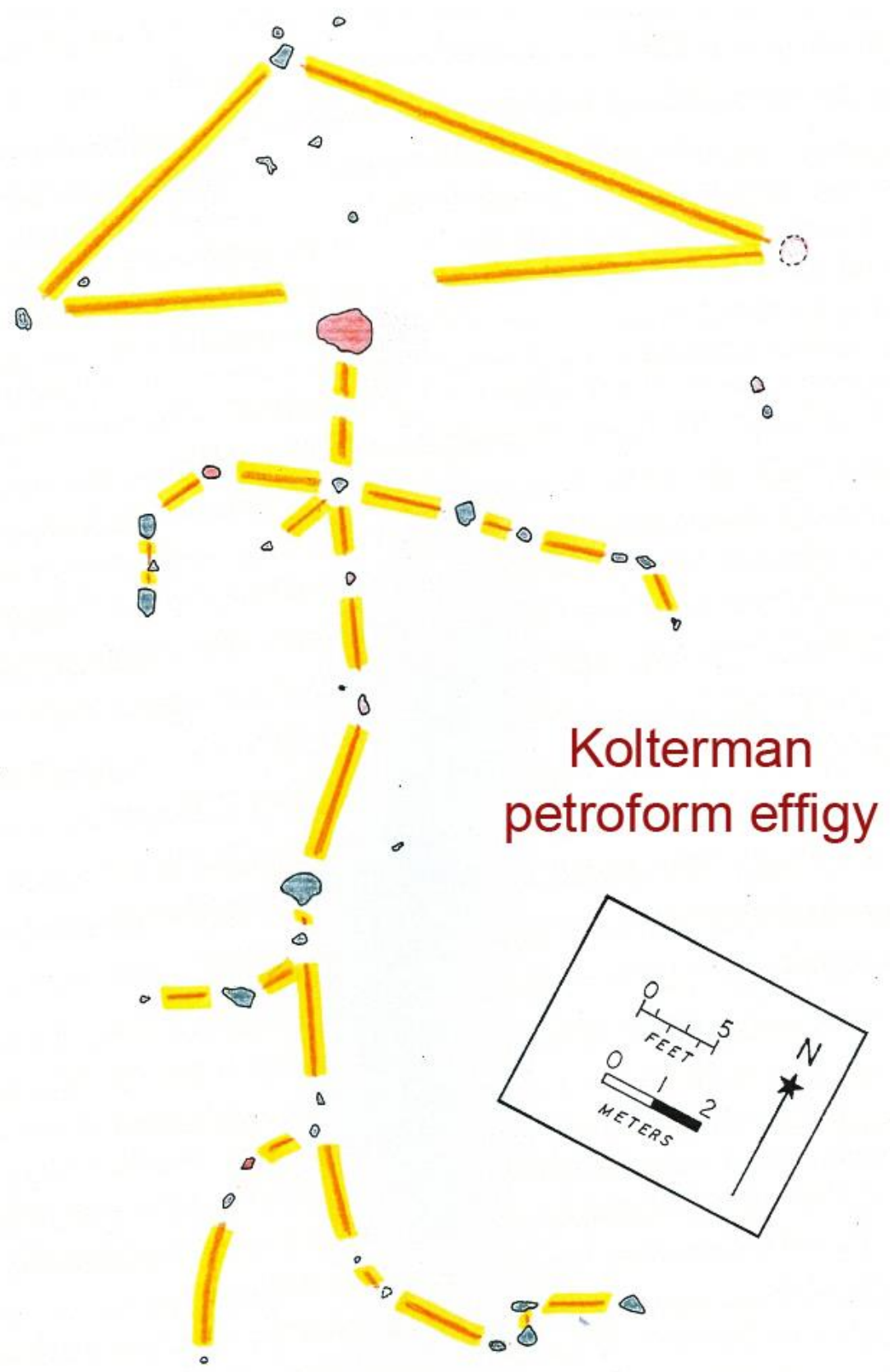

Figure 21. Map of the Kolterman Star-Being, a male, human-like lithic effigy with a serpentine body and redcoloured, bison-shaped headstone.

The Star-Being is located on a small hill on the east side of the Horicon marsh (Figure 22). From it the entire (north to south) length of the Horicon Marsh basin to the west can be viewed. Save for some trees to the west which have grown up in the past 100 years, the north to south vista presents a continuous view with a near $0^{\circ}$ elevation toward the entire western horizon. Over the years, the western portion of the site has been destroyed mainly by road construction and partly by agricultural cultivation. The land containing the remaining mound group has never been cultivated, only pastured. 


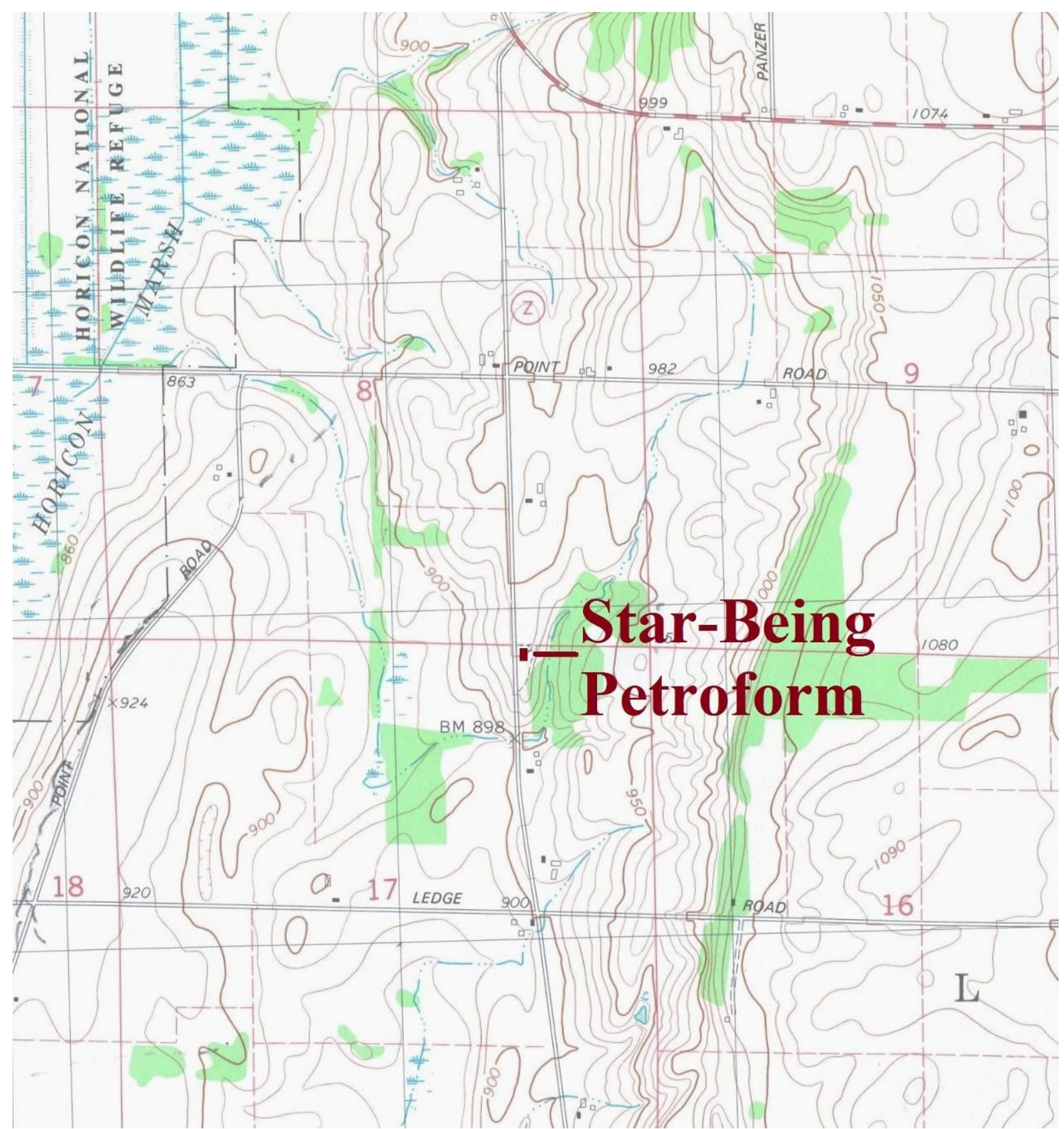

Figure 22. Portion of a United States Department of the Interior Geologic Survey, Mayville North Quadrangle, Wisconsin, 7.5 Minute Series (Topographic) map showing the location of the Star-Being petroform hill on the east side of the Horicon Marsh. Contour lines are at 10 foot intervals.

\subsection{Star-Being headstone description and solstice alignments}

The Star-Being headstone (Figures 21 and 23), like the Starman headstone (Figures 2 and 9), is a deeply weathered, red-coloured (red rhyolite porphyry) bison-shaped rock with a cleaved, flat back end, aligned to face the summer solstice sunrise (Figures 23, 24 and 25). It is considered to be two-headed (Figure 25), to the Cheyenne, haztova hotoxceo or "two-faced [star people]" and to the Lakota, Anukkite or "face on both sides (Powers 1977: 197; Schlesier 1987: 79). 

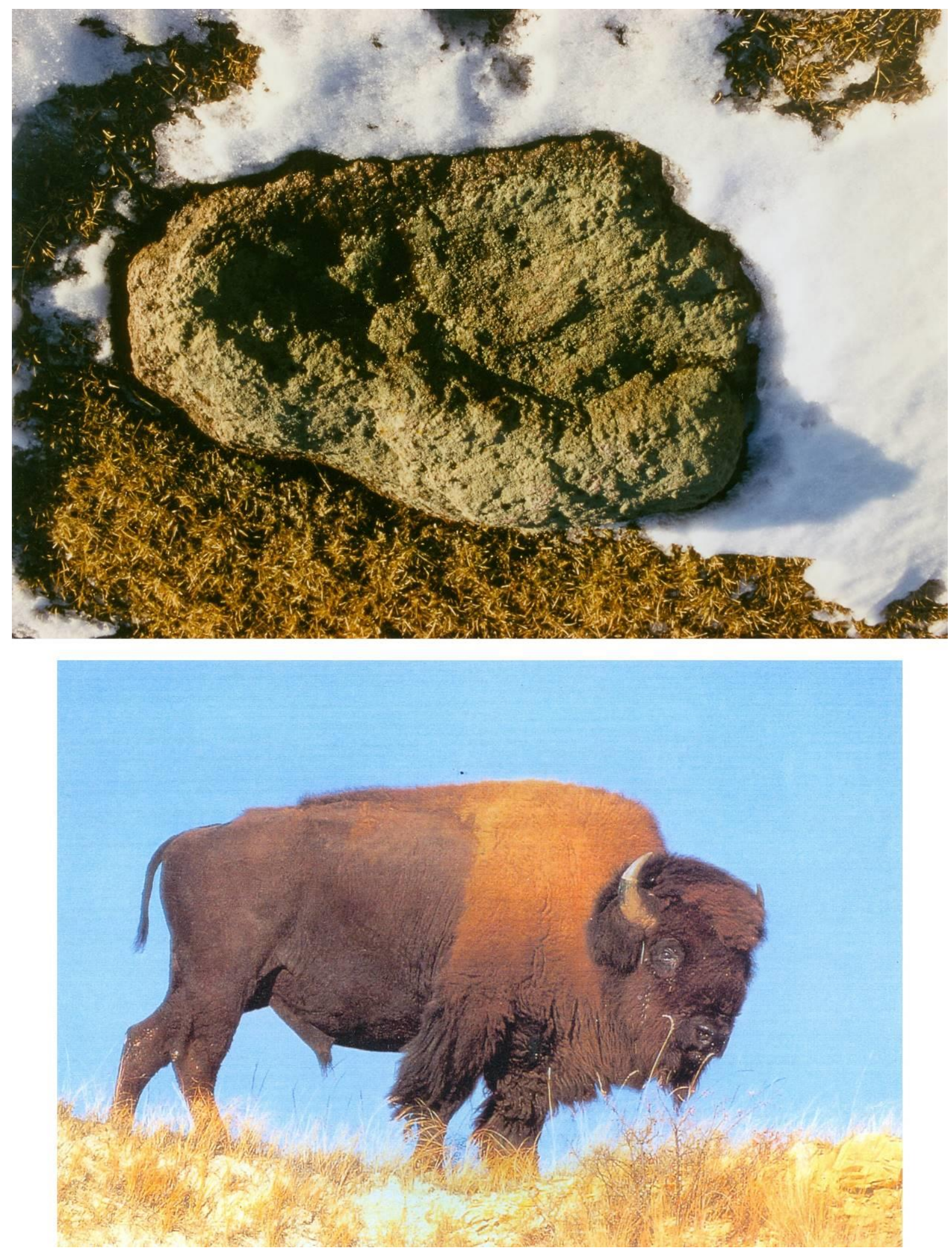

Figure 23. Photo (top) of the highly weathered, Star-being bison-shaped headstone. In the grazing light of the late Fall and early Winter the eye detail and what may have been a horn are apparent. Note the cleaved flat, straight and perpendicular back (west) end and dip like that on buffalo in viewed in full profile (bottom photo). When fresh, the red rhyolite porphyry headstone was a deep red color. 


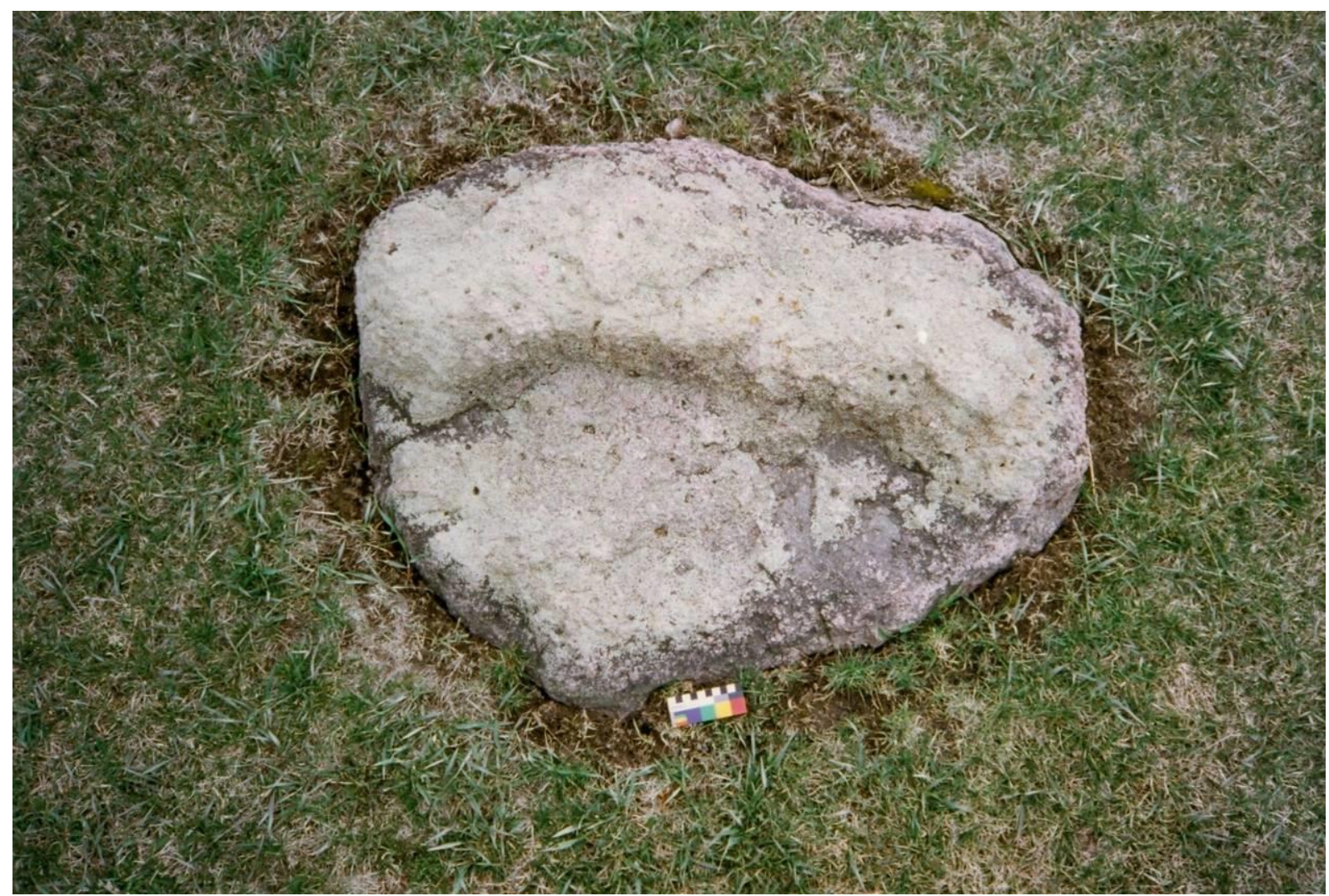

Figure 24. A direct, overhead view of the Star-Being headstone showing its dual humps and flat, cleaved straight rear end.

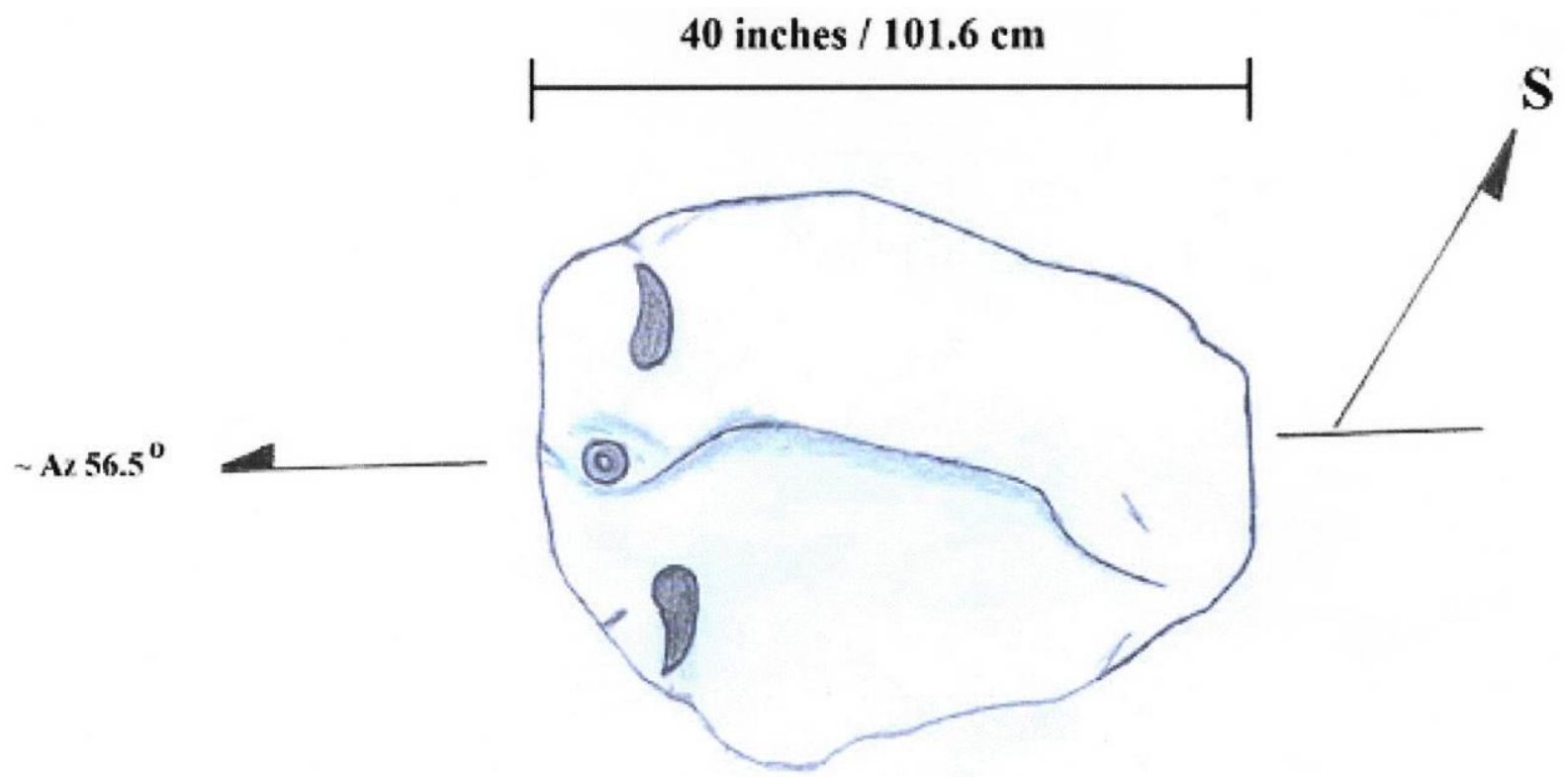

Figure 25. Outline drawing the two-headed bison effigy rock with horns and eye added to suggest the dual bison profile viewed from either the north or south. At the latitude of Kolterman, the azimuth $56.5^{\circ}$ is near the $0^{\circ}$ elevation of the first flash of the summer solstice sunrise.

Because the summer solstice sunrise is now blocked by vegetation, the reverse azimuth, i.e. the winter solstice sunset, was utilized in order to confirm the accuracy of the alignments (Figures 26 and 27).

Viewed across the Horicon Marsh, the sun is seen to set on the horizon at $0^{\circ}$ elevation. This is another likely reason why the location was chosen for the site. 


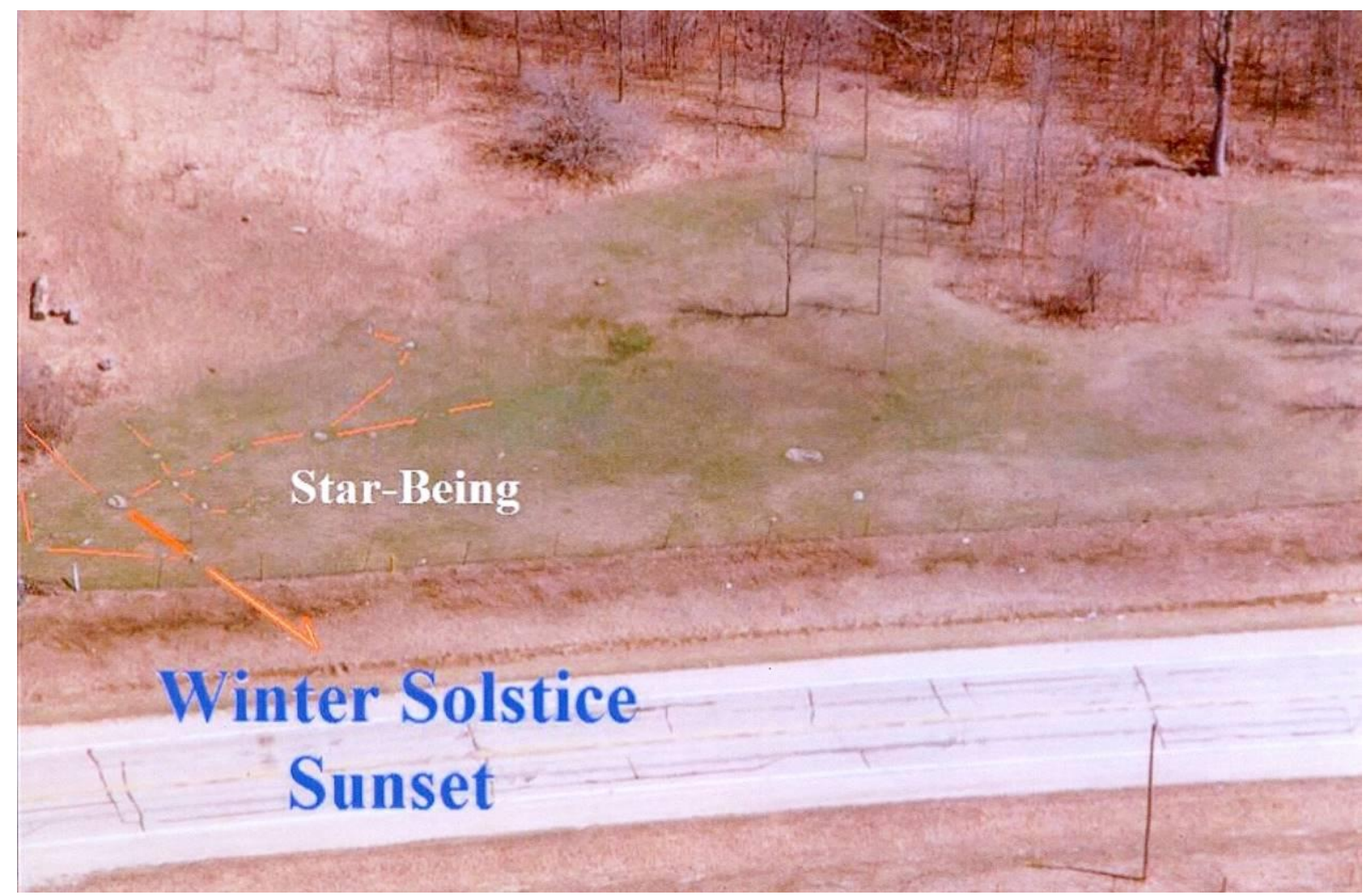

Figure 26. Aerial view of the Star-Being lithic outline or petroform with 'helper lines' and the direction of the winter solstice sunset viewed overlooking the aligned, bison-shaped headstone and an aligned rock (see Figure 27). Road construction likely destroyed others in the alignment.

When mapping the lithic outline or petroform, the upper body bending north-west from a lower body south-to-north alignment, the 'hooked' leg terminating with the large rock 'stingers', a 'tail' stone, a triangle of stones surrounding the headstone and the sinuous body shape are all highly diagnostic features for someone with a background in astronomy. It is a very recognizable pattern which can be found in the night sky. The 'stickman' effigy on the ground at Kolterman can be seen as a star or rock mirror-image of the constellations that we call Scorpius and Libra (Figure 28).

\subsection{Thunderbird traditions}

A natural question is why would people create a mirror image of these particular stars or stellar pattern? The answer may lie within the thunderbird traditions and stories of the Plains and other American Indian together with the seasonal rising and setting of the stars in Libra and Scorpius relative to the sun during ancient times. 


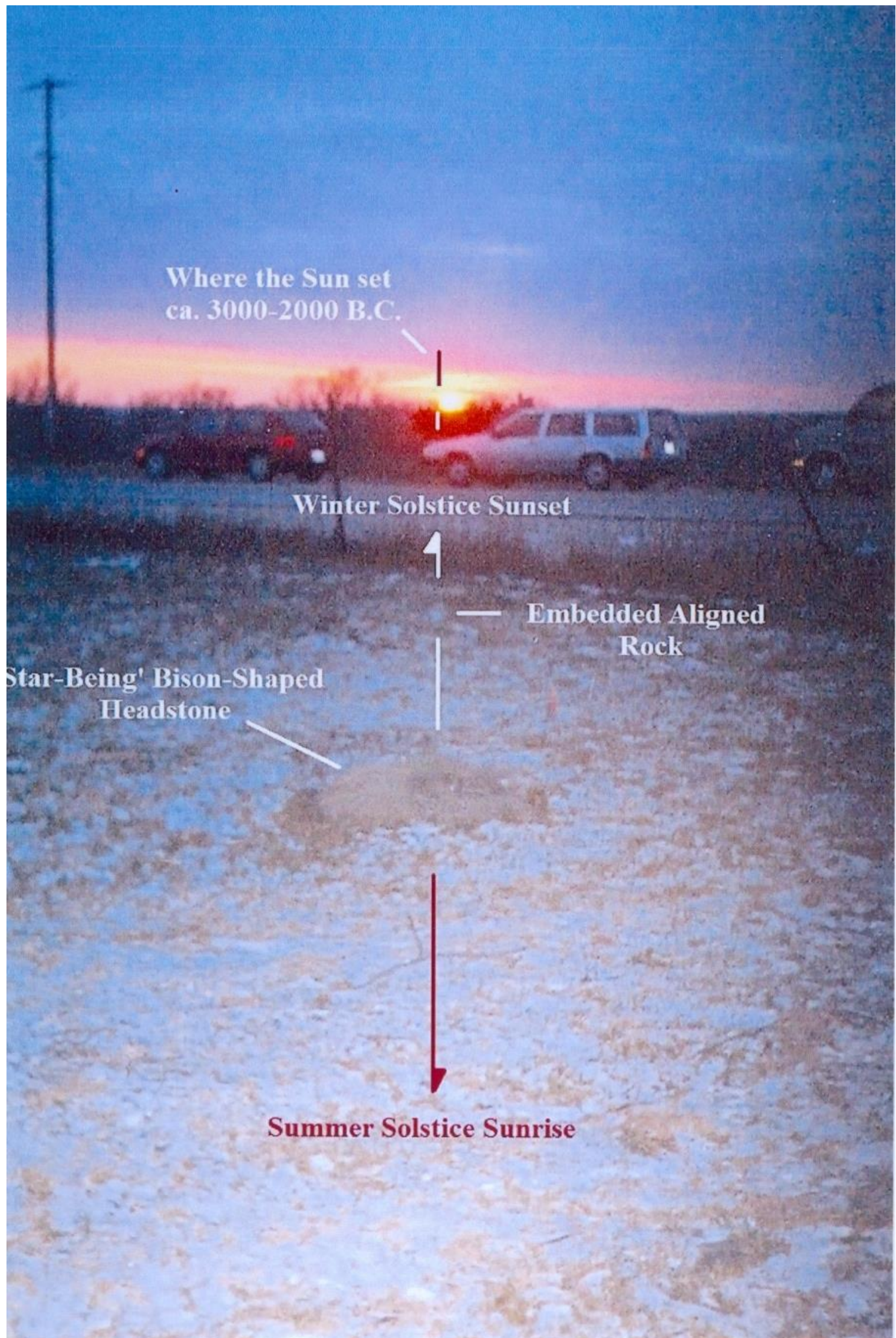

Figure 27. The winter solstice sunset overlooking the Star-Being headstone and aligned rock (Figure 26). Note the full solar diameter shift to the right or north of the alignment, which is the effect of 4000 years of the shift of obliquity of the ecliptic. 


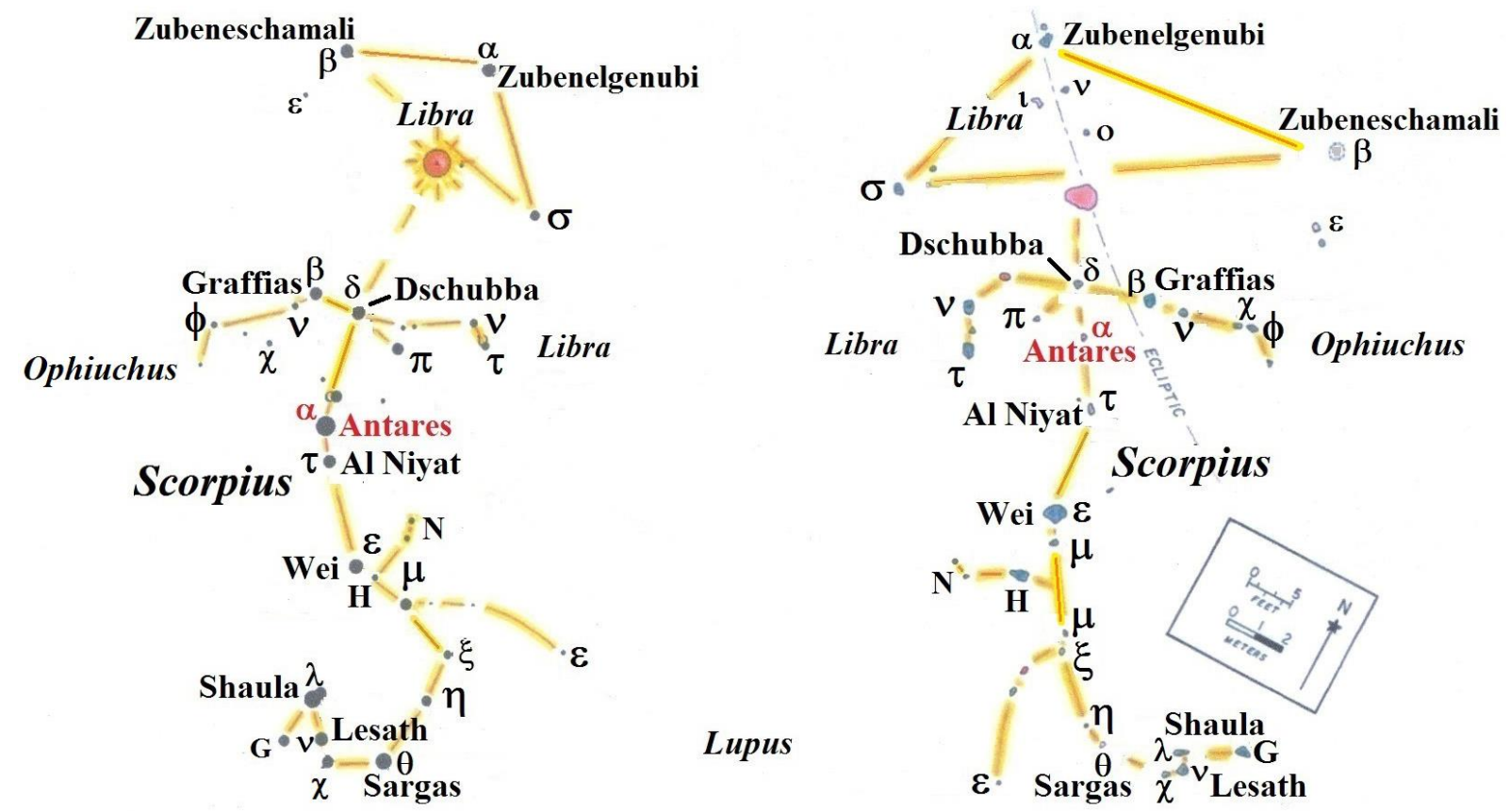

Figure 28. Illustration showing the Kolterman Star-Being (at right) as a mirror image of the western constellations Scorpius and Libra. Note that the individual stones in the lithic form can be annotated 'rock for star' when compared to the mirrored star map. The Star-Being's red-coloured, bison-shaped headstone is in the same location in the stones making up the constellation that we call Libra as was the Sun during the autumnal equinox sunrise about 4000-2000 BCE.

One of the most ancient and widespread traditions amongst Native American people is the thunderbird tradition (Grant 2000: 311; Owusu 1997: 132-133, 178-179, 187-188). Thunderbird stories are part of almost every tribal mythology. They are especially prevalent in the Midwest and Great Plains where severe thunderstorms occur on a seasonal basis. Thunderbirds are said to arrive in the spring of the year, their coming announced by the seasonal weather changes that produce thunderstorms. Their return brought the rain each spring to herald the growing grass, blossoming flowers and to make the berries large and sweet (Cooper 1975: 9-10; Grinnell 1972: 95-96; Mails 1972: 93). Lightning is said to flash from their eyes, many times depicted in a zigzag shape which can also represent a serpent motif, while thunder is said to be the noise of the battle between the thunderbird and giant serpents who live under water. Like the thunderstorms that subside in the autumn, it is the season when the thunderbird is also said to depart, going south (Cooper 1970: 9-10, 146, 193; Grinnell 1972: 95-97; Taylor \& Sturtevant 1996: 46-47, 477-478). For the Native American people there were strong ceremonial associations between the thunderbird; the number four; the four seasons that quarter the year; animal migrations; and the Sun dance (Cooper 1975: 184, 191-197; Grinnell 1972: 262- 263; Powers 1977: 97; Williamson 1989: 234).

Not surprisingly, Thunderbird traditions and rock art representations in the upper Midwest and north-eastern United States are very similar if not identical to those on the Great Plains with some greatly resembling the Star-Being. Like those attributed to the Starman, the reason for the similarities is that many of the Algonquin and Siouan people, including the Lakota and Cheyenne, migrated to the Plains from the upper Midwest taking their traditions with them (Powell 1969: 26; Schlesier 1987: 50-51). Three reoccurring archetypical elements linked to the thunderbird abound in American Indian mythologies and traditions. They are the thunderbird or Thunderers, giant serpents and a cultural hero who may be half human and half animal, and, many times, a 'Star-Being' who is also a cultural hero. T.E. Mails (1972: 92) remarked that "Many tribes regarded certain bright stars as men ..." and Father Florimund J. 
Bonduel said in 1855, "They [the Indians] look to the stars which they worship as guardian gods" (Rosholt \& Gehl 1976: 226). All three elements are incorporated into the Star-Being.

Lewis Spence (1994: 152-159,172-173,201-203) recites many stories of people marrying or being abducted by 'star-people'. These unions often times produced offspring who possessed powers or traits beyond those of ordinary humans. In Lakota cosmologies and traditions, stories of the cultural hero Fallen Star linking him to prominent landmarks and the sky prevailed (Bender 2011c: 168-170, Goodman 1992: 3). In one story Fallen Star (whose father was a star and mother human) had to recover the Chief"s arm lost to the "The Thunderers" or Wakinyans (Goodman 1992: 217-220). Fallen Star recovers the arm from "The Thunderers" in the Spring of the year. The Chief's arm was seen in select stars in the constellation of Orion which is seasonally 'opposite' the constellation of Scorpius. In the Spring, Orion sets early in the evening with Scorpius rising early in the morning. Therefore, the Chief's arm story is an allegory for earth renewal and fertility timed to seasonal rising and setting of the stars. The Greek myth of Orion and his nemesis, the Scorpion was born of this same seasonal and stellar sky division (Krupp 1991: 136-137). But rather than seeing Orion and Scorpius rising and setting, Indian people saw other shapes and invented other stories, i.e. the Chief"s arm and "Thunderers".

Another Plains Indian cultural hero, Clot-of- Blood, was also recognized in the stars. Clot-of- Blood, a buffalo fetus born of man, was a half man-half bison hero acting on behalf of man. He was identified with the Great Nebula in Orion's 'sword' (Kehoe 1992: 207-214). Serpents, thunderbirds and the number four are main elements in the Clot-of-Blood stories. In Gros Ventres stories where he is known as "Blood Clot", Clot-of-Blood slays four evil foes including a giant serpent but cannot completely overcome a thunderbird with whom he strikes a truce. The thunderbird is Bha'a, the giver to the Gros Ventres of the Feathered Pipe during a severe thunderstorm. The Feathered Pipe is a sacred relic used in renewal ceremonies (Cooper 1975: 482-487). Again, the parallels to Orion and likely Scorpius as Bha'a, a thunderbird (bringing storms) not being able to overcome one another and thus separated are remarkable.

Many Native American myths and stories about the stars and constellations are likely as old as those of Orion and Scorpius. According to Schlesier (1987: 15), the Tsistsistas (Cheyenne) retain dim memories and knowledge of "stars and all their different groups ... gradually [being] forgotten" and that "... star constellations provided signals at certain times for Tsistsistas actions ... and some star clusters are considered Tsistsistas spirits, relatives in the sky". As Ralph Redfox first remarked after viewing the "star-being' petroform, the site and then the maps, "There are old stories I heard about this as a boy. I can't remember them exactly, but they were about star people and what is here, this Thunder being" (personal communication, April, 1998).

The "old stories" that Ralph Redfox mentioned are Cheyenne stories of the origin of their cultural hero Motseyoef or "Sweet Medicine" (Hoebel 1960: 7; Powell 1969: 26; Schlesier 1987: 78). Sweet Medicine origin stories resonate with the same archetypal elements common to the Fallen Star and Clot-of-Blood stories. Sweet Medicine met, then was instructed and given his 'medicine' by Nonoma, represented by the red star Aldebaran, and his wife Esceheman, represented by the white star Sirius. Their daughter was Ehyophstah, represented by the blue-white star Rigel. Before meeting Nonoma and Esceheman, Sweet Medicine and a companion were rescued from a giant serpent called an axxea that had severely injured his companion. The rescuer, Nonoma, killed the axxea and his wife Esceheman butchered it. The companion was then taken to their (Wolf) lodge where he was healed or 'renewed'. While in the Wolf Lodge, both Sweet Medicine and the companion were give white flint knives and ate from very white stone bowls (Schlesier 1987: 77). On a related note, the Blackfoot, another northern Plains tribe, identify Clot-of-Blood's white flint knife with Orion's nebula (Kehoe 1992: 212). 
Once again there is a symbolic relationship with the stars in or near Orion as slayers who vanquish a giant serpent (Scorpius?) and then hold renewal ceremonies for human beings. Furthermore, in yet another story, Sweet Medicine uses his 'medicine' to vanquish giant beings called haztova hotoxceo, in which haztova is translated as "both sides of the head" and hotoxceo as "star" or "two face star people" (Schlesier 1987: 79), reminiscent of the twoheaded bison effigy headstone of the Star-Being (Figures 21 and 25).

The parallels of the archetypal elements in the cultural hero stories to the Kolterman StarBeing are almost overwhelming. The Star-Being may represent the perpetual transformation of metaphor (serpent) on metaphor (thunderbird) on metaphor (half human and half bison); a Thunderer configured in stone linked and timed to the perpetual movement of the stars. If so, it is based on as ancient a Native American tradition as can be found and their reverence for a natural object's ability to transform and change.

\subsection{Dating the Star-Being}

Dating of the Kolterman Star Being is also based on associations, not absolute dating techniques. Like the Starman form, all of the individual rocks placed on the original land surface are now deeply embedded with only the top of the rocks exposed. They are also highly weathered from exposure to the atmosphere and differential weathering, the surfaces not exposed still smooth and retaining the rocks texture and colour.

The 'dual bison headstone' location may provide another valuable clue as to possible origins and age of the Star Being. Between 4000 and 1000 BCE, the autumnal equinox sun rose into the background of stars we now call Libra (Figure 29) although, at the time, Libra was still part of Scorpius (Allen 1963: 366; Cornelius 1997: 105; Sesti 1991: 440). People who possessed astronomical knowledge of knowing where the sun rose relative to the background of stars from season to season were available, and accomplishing the feat is not that difficult (Goodman 1992: 48-49; Krupp 1991: 132-134; Schlesier 1987: 71-72).

From the historic record and precession data, the best-fit date for where the Star-Being effigy headstone (as the sun) is located relative to its body and 'Libra-like' triangle of stars is between 4000 and $1000 \mathrm{BCE}$ (Figure 28). The half-degree of shift of the obliquity of the ecliptic (one full sun diameter to the north) observed for the winter solstice sunset (Figure 27) also supports the precession date of the autumnal equinox sunrise for the proposed date of 2000 BCE (Aveni 1972; Meeus 1991: 135-136).

Based on these factors and others, a late Archaic age is proposed for the Star Being, coeval with the Starman's early date of 2000 BCE.

The Star Being could, however, be older. This is based on the extreme differential weathering surfaces of some of the rocks (especially seen in the headstone), observed shift of the obliquity of the ecliptic, and on the precession dates for the autumnal equinox against the background of stars that the Star Being is proposed to mirror (Figures 28 and 29).

Over the past 175 years, thousands of prehistoric artifacts have been discovered in the greater Horicon Marsh area. Like those recovered from the proximal habitation sites near the Starman site, the vast majority date from the Archaic period (Steinbring et al. 1995), dated by their style, shape and workmanship.

Typical of the artifacts are those from a family member's collection found on the family farm over the past 100 years in fields to the west of the Star-Being site (Figures 30 and 31). Dating from the mid to late Archaic time period circa 6000-1500 BCE (Goldstein \& Osborn 1988; Stoltman 1986), the collection also includes full-grooved stone axes, which is a hallmark of the Archaic period (Quimby 1960: 43-44). 


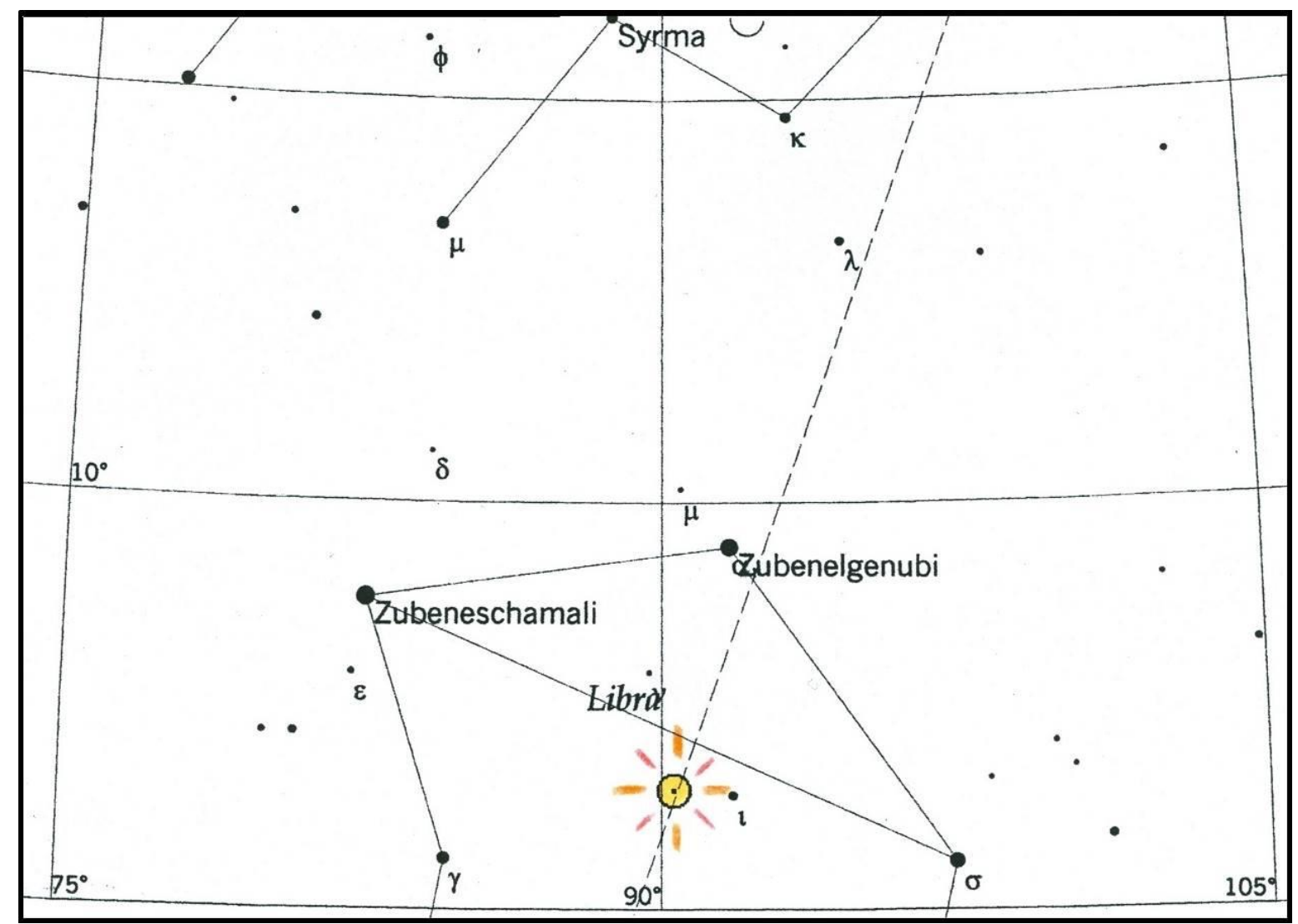

Figure 29. The Autumnal equinox sunrise in the constellation of Libra in 2000 BCE.
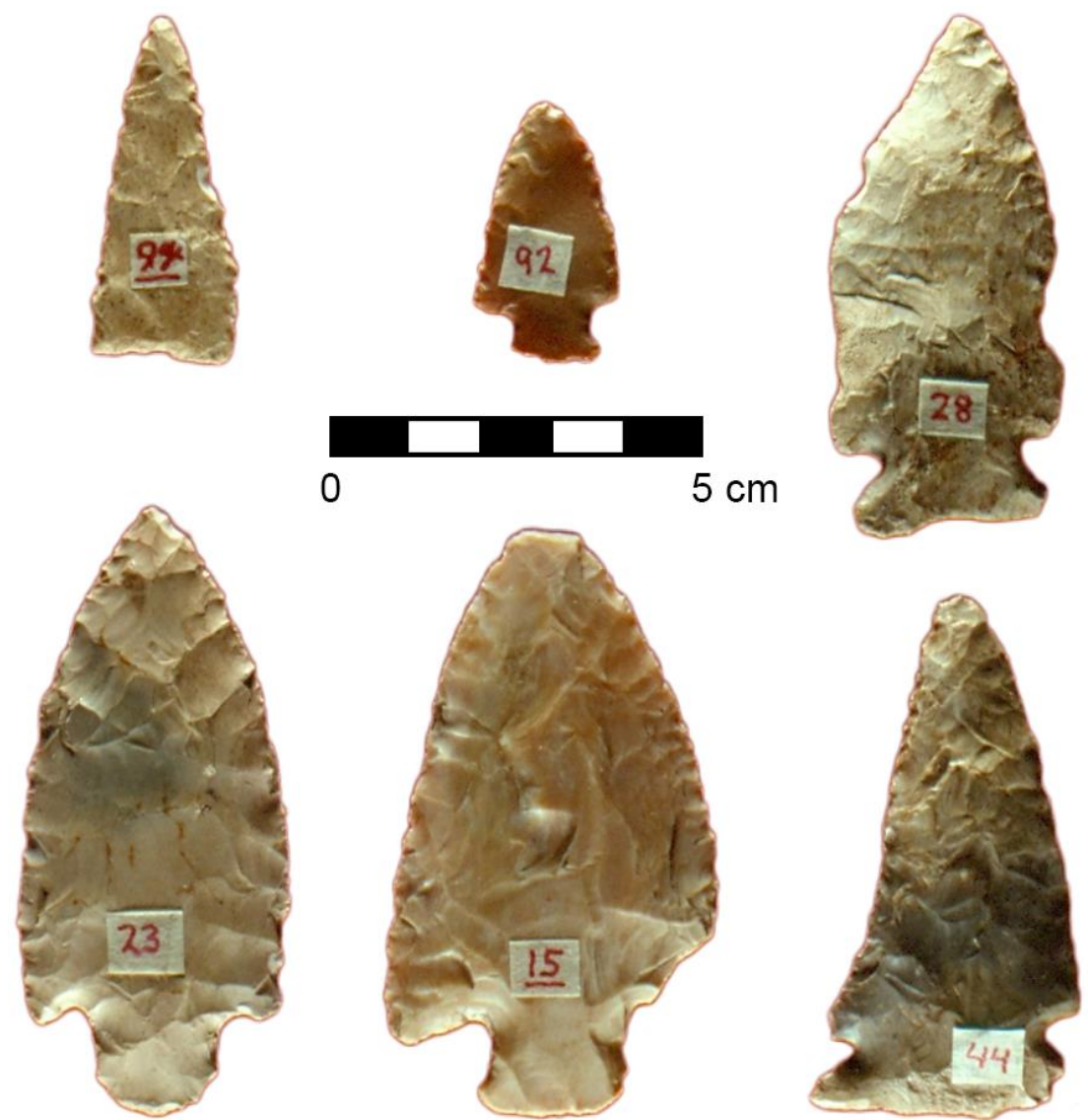

Figure 30. Middle to late Archaic spear points and knives from a private collection gathered by family members on the Star-Being farm and property. Made from local cherts, they date between 4000-1500 BCE. 

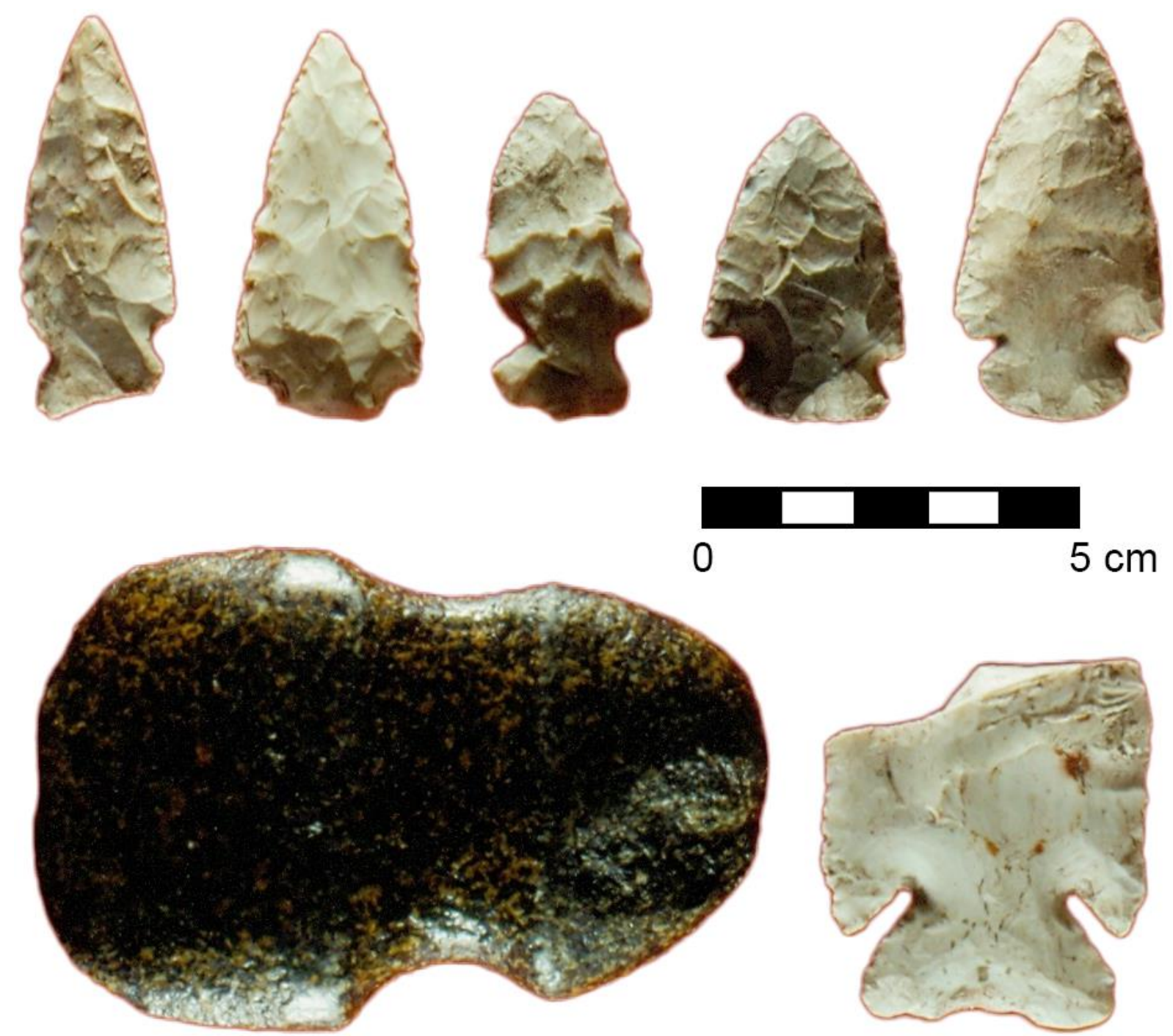

Figure 31. Archaic period spear points, knives and small axe from a private collection gathered by family members on the Star-Being farm and property. The axe is made of gabbro, the points from local cherts. The two blades at right are early Archaic dating approximately 6000 BCE. All others including the axe date between 3000-1000 BCE.

There is, however, one other corroborating date supported by stellar precession. Since 2004, continuing field work, the mapping of all the rocks on the north end of the site, and further examination of Plains Indian stellar traditions with their attendant cosmologies have produced a larger, if not more complex, picture of what may be reflected in 'the above.' Located a short distance to the south of the Star-Being are two bison-effigy rocks (Figure 32). One, named "Bruder's rock" is a large, north-facing bison-effigy rock. The other is a smaller although still large rock that is aligned east-west.

Both bison effigy rocks are exactly located and spaced in relationship to the Star-Being petroform mirror-image of Scorpius when the bright stars Rigel Kent (alpha Centauri) and Hadar (beta Centaurus) culminated during the vernal equinox ca. 2000-4000 BCE No longer visible at the latitude of the site $\left(43.5^{\circ} \mathrm{N}\right.$. Latitude), both bright stars were highly visible riding low above the horizon in the night sky prior to 1200 BCE (Figure 33).

Lakota informants say that the two bison effigy rocks are lithic representations of the White Buffalo Calf woman with a calf (Dinah Crow Dog and Leola One Feather, personal communication). Both are coming from the south as bright, white stars - white being the Lakota sacred colour for the direction south (Powers 1977: 49). Moreover, the north-south 
and the east-west alignments of the bison effigy stones quarter-divide space, in keeping with a cosmic compact representing the universe. They are a strong female counterpart to the very masculine Star Being (Powers 1977: 49-50; Sundstrom 2004: 81-87). If so, like the Thunderbird, the southern stars may represent the buffalo that the White Buffalo Calf Woman changes into (Powers 1977: 196-197), coming back from the south in the spring of the year along with the Thunderbird, the rain and the greening of the grass - all indicative of the world being reborn.

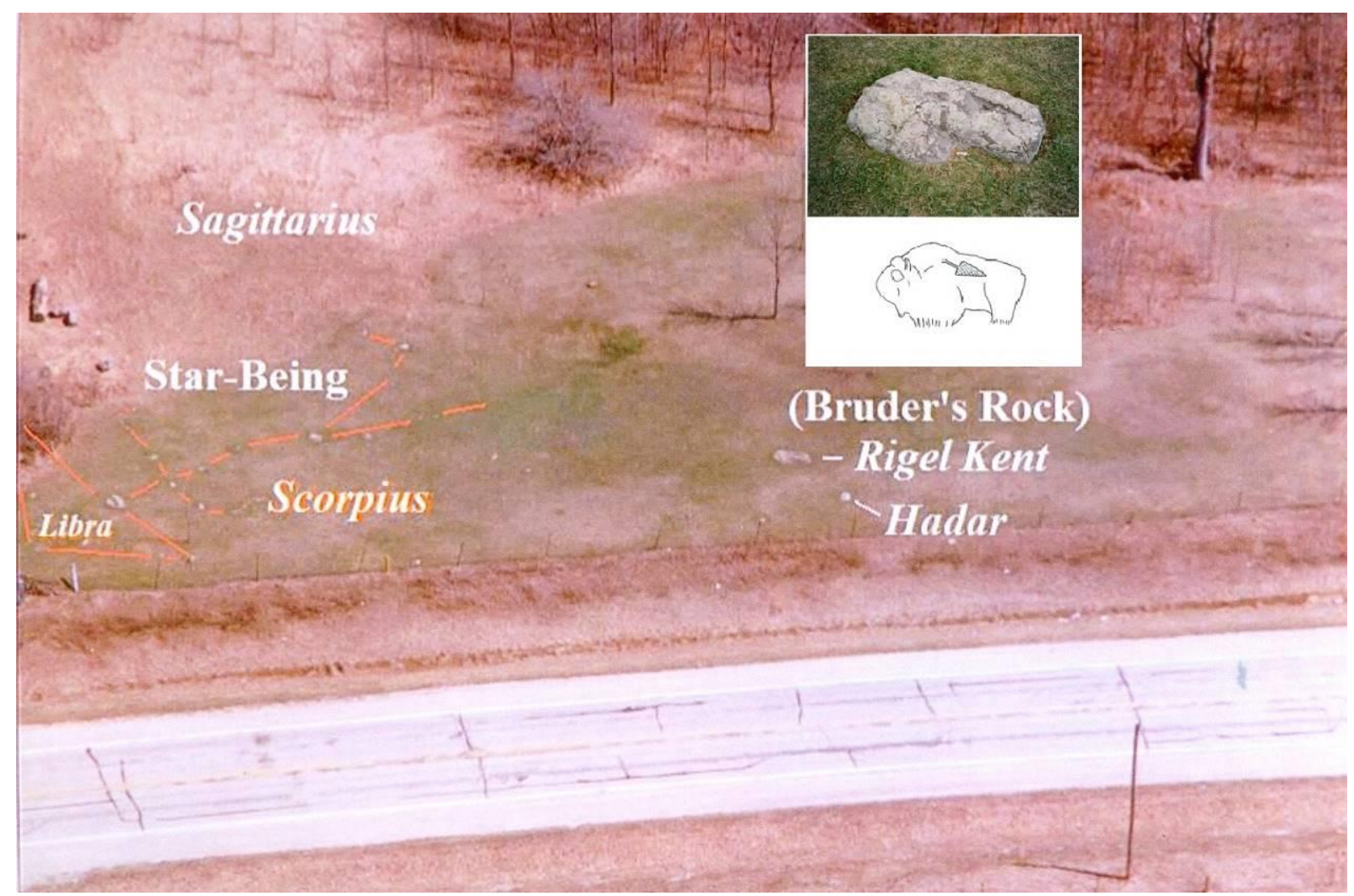

Figure 32. Aerial photograph of the Star-Being as a reflection of Scorpius and Libra with the two bison effigy rocks. Bruder's rock (see inset) is identified as the bright star Rigel Kent (alpha Centauri), the smaller one to the south-west of it identified as the star Hadar (beta Centauri). The constellation Centaurus is no longer visible at the northern latitude of the Star-Being site, a consequence of precession of the equinoxes. View is looking east with north to the left.

\subsection{As above, so below}

In 2007 a small but fortuitous grass fire exposed more fully the tops of the deeply embedded rocks to the immediate east of the Star-Being lithic outline. Because of their location on the ground relative to the Star-Being and the stars in the night sky east of Scorpius (Figure 34), it was conjectured that the rocks may represent the stars of the constellation that we call Sagittarius. After all the rocks were compiled into a map (Figure 35), it became apparent that the somewhat elliptical shape could be interpreted and configured as a mirrorimage of the stars in the area of the constellation Sagittarius. When keyed into the overall Star-Being map, the picture that emerged was one with the long axis of the 'ellipse' aligned to the summer solstice sunset as viewed overlooking the Star-Being headstone. The alignment and the event were confirmed the same year. 


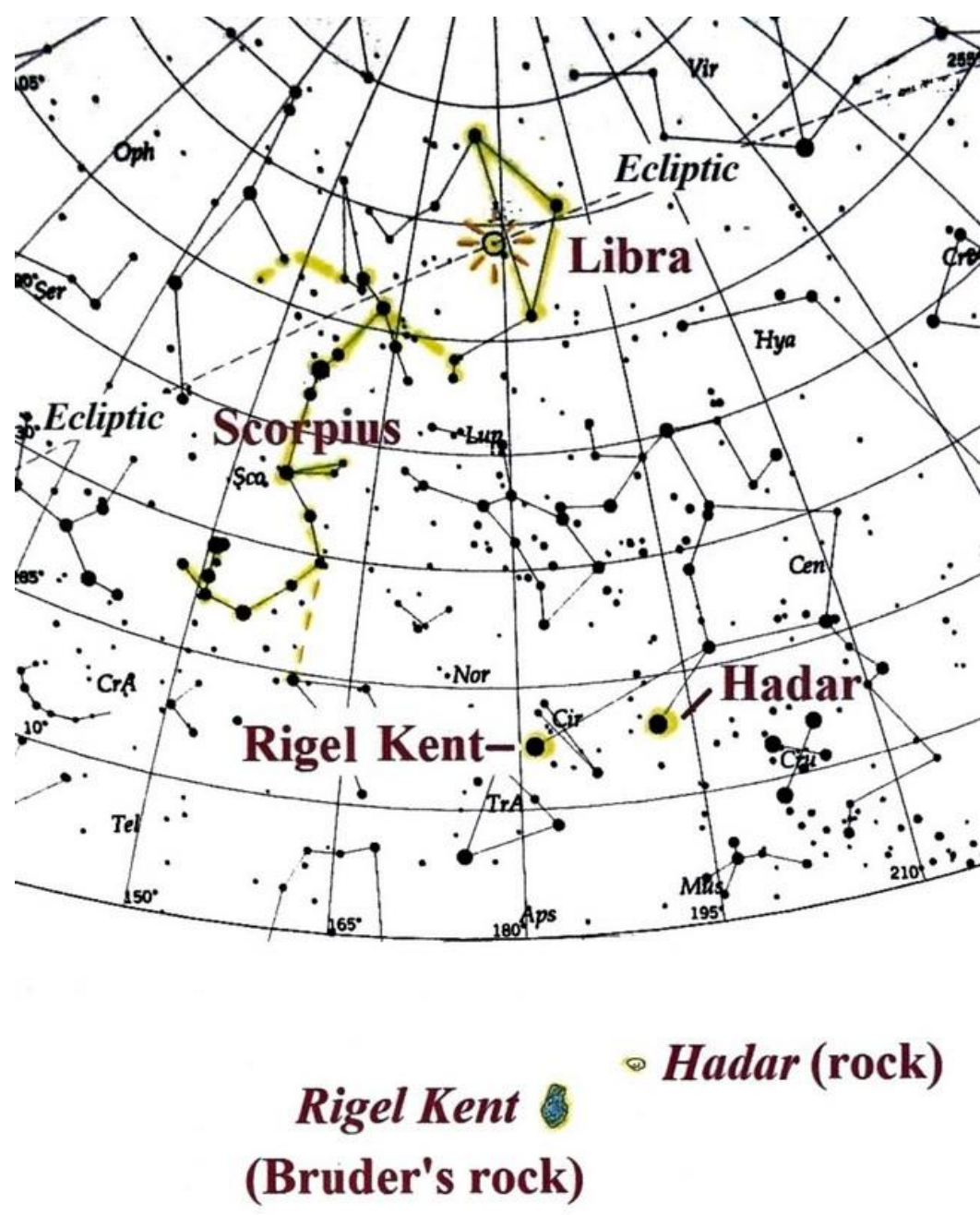

\section{(Bruder's rock)}

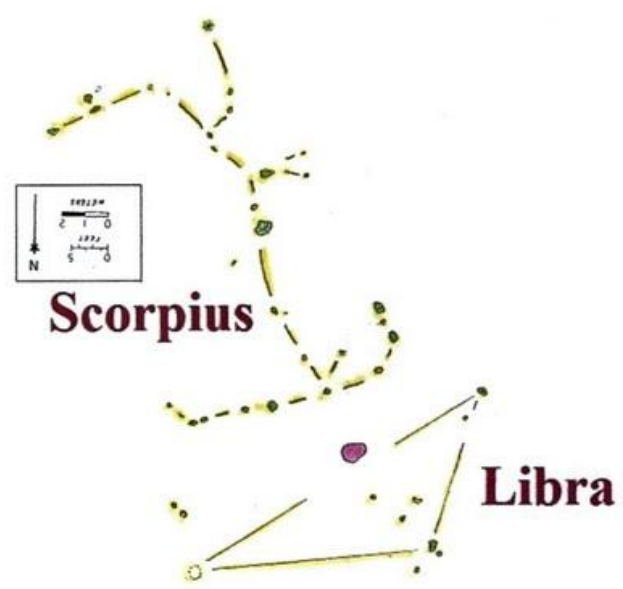

Figure 33. The stellar precession map (at top) shows the where the autumnal equinox sunrise would have been relative to the background of stars in Libra ca. 2000 BCE. Of note, the bright stars Rigel Kent and Hadar were at or near culmination near midnight during the time of the vernal equinox ca. 2000 BCE. The illustration (at bottom) is a map of the Star-Being with the two bison effigy rocks including Bruder's Rock (see Figure 32). Both effigy rocks and the Star-Being are in an almost exactly mirrored or reflected location relative to Rigel Kent, Hadar and Scorpius in the night sky. The location of the Star-Being headstone likely indicates where the sun rose into Libra at the time of the autumnal equinox between 4000-2000 BCE, the proposed date of origin of the Star-Being and other petroforms found at the site (Bender 2004). 


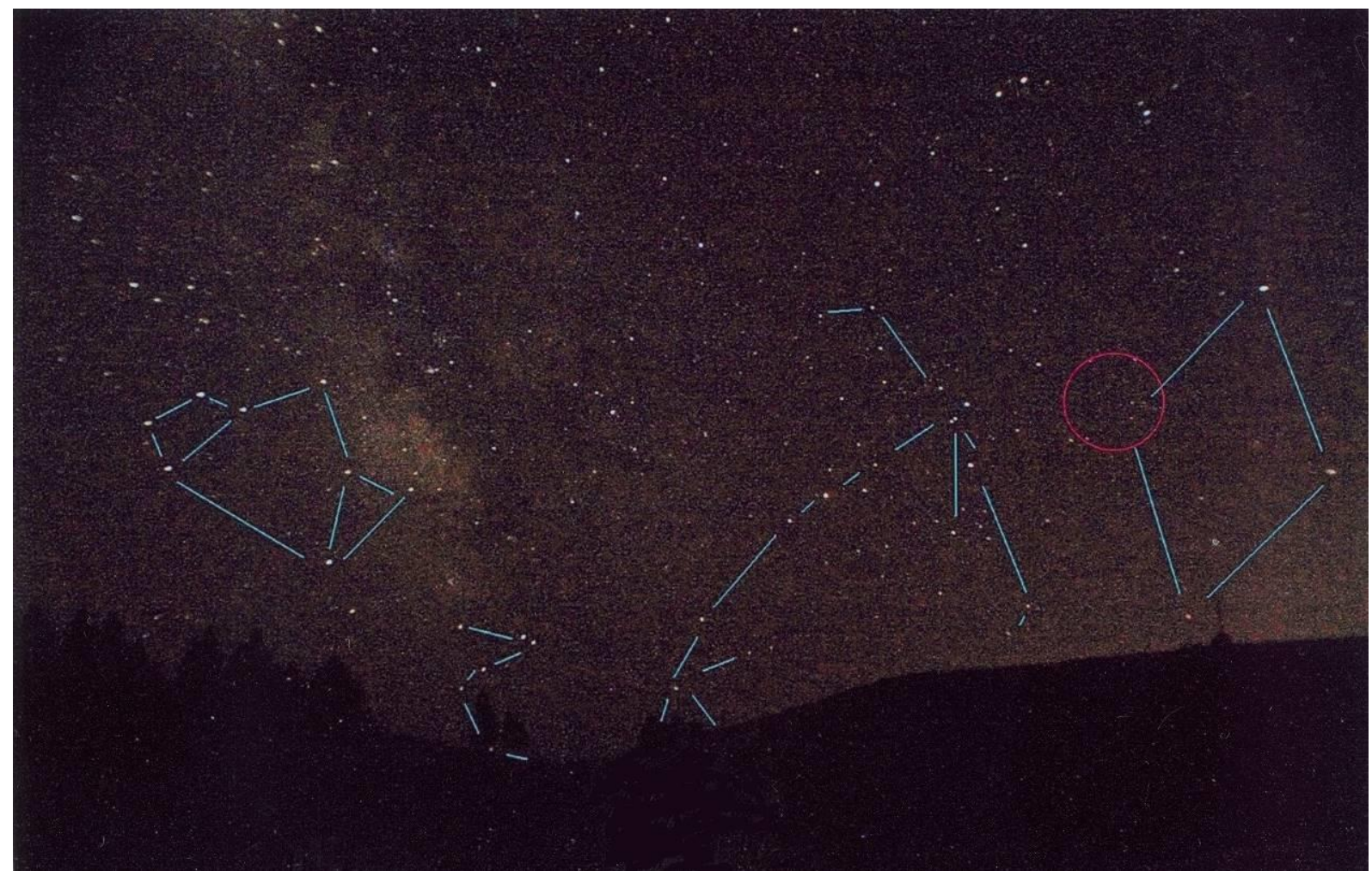

Figure 34. Photo of the southern night sky from the dark skies of the Pine Ridge reservation in South Dakota. The 'helper lines' show the constellations of Sagittarius, sometimes known as the 'teapot' (at left), with the Milky Way the 'puff of steam' coming from the spout and the stars in Scorpius configured as the Star Being (at center). The diamond shape at right is Libra. The red circle shows where the Autumnal equinox rose in the background of stars ca. 4000 BCE (see Figures 29 and 33).

The mapping of the lithic form that we call Sagittarius as an archer or 'the teapot' does not conform to Plains Indian astronomical convention, but perhaps could represent a humped animal, e.g. a bison (Leola One Feather and Iegor Reznikoff, personal communications).

This conjecture may not be unreasonable when Lakota and Plains Indian cosmologies are factored into the discussion. It is in the night sky directly above the 'spout' of the 'teapot' where the richest part of the Milky Way streams upward (Figure 34).

In the ancient bison culture and associated cosmologies, the Milky Way was perceived as the visible breath or spirit of bison (Sundstrom 2004: 81-87). The Lakota say the stars are wakan, "the Holy Breath of the Great Spirit" and like the Milky Way or bison's breath, considered sacred (Goodman 1992: 1, 21, 23, 56). Because of these provocative features and others mapped on this site over the past 20 years, the rocks so carefully placed on the ground so long ago may well express the most complete indigenous 'map' of the cosmos laid out in stone known to exist.

\section{Discussion and Conclusions}

In the heavily glaciated south-eastern corner of Wisconsin, glacial erratic rocks and boulders were utilized to create petroform sites, i.e. with forms outlined lithically. At two sites, the Starman and Kolterman Star-Being, rocks were incorporated into giant human-like forms. The individual colour and form of chosen rocks were a vital part of the design. Both sites are a reflection of a select part of the night sky where the people 'anticipated' certain and predictable events timed to the seasonal rise of the sun and stars. Although they may have reflected stars in the night sky in the physical sense, each was a physical embodiment of 
cosmologies that had originated in the upper mid-west of the United States transported to the Great Plains millennia later.
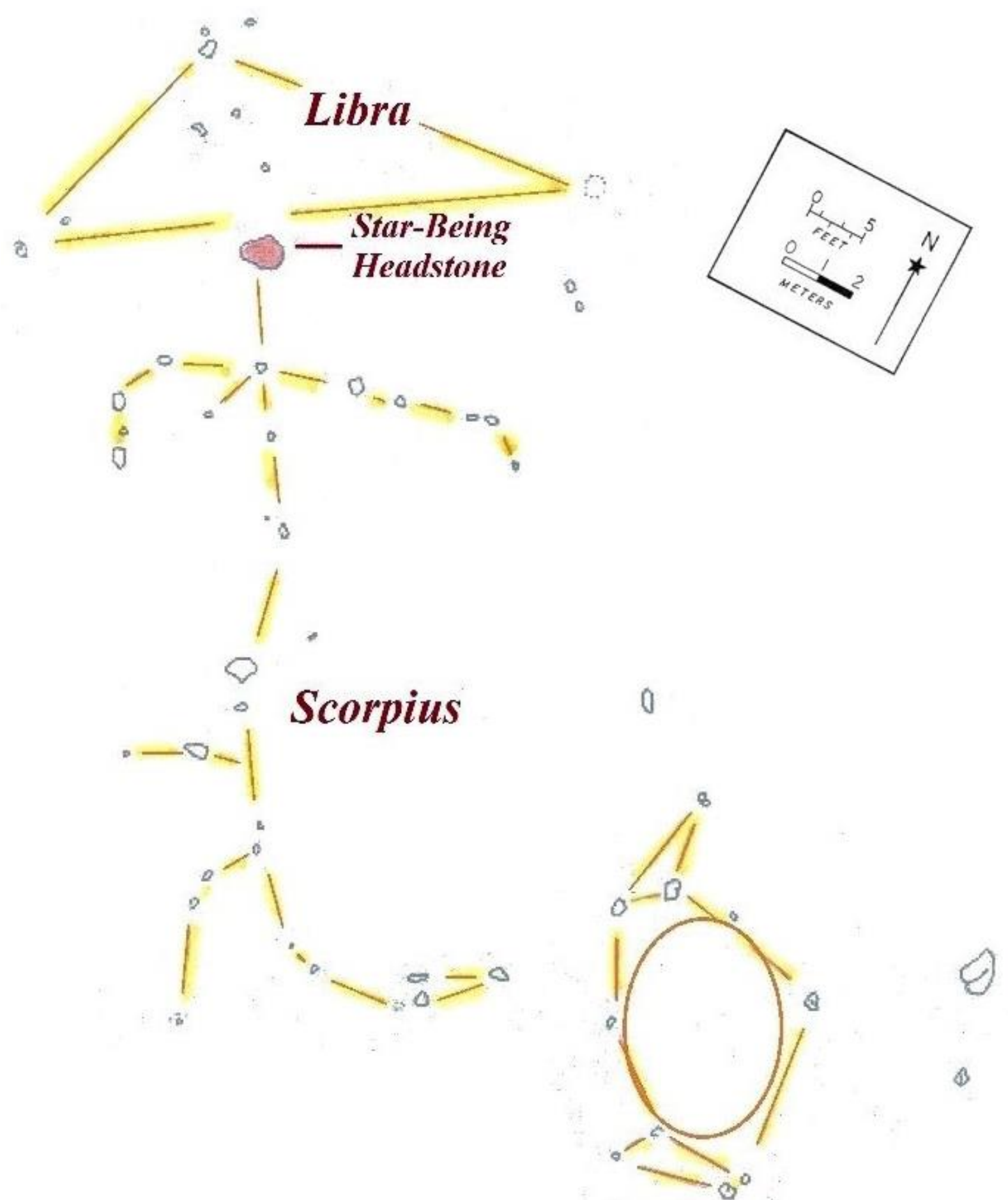

4

\section{Sagittarius}

Figure 35. Compiled map of the deeply embedded rocks showing the 'ellipse' as Sagittarius with 'helper lines' added and the Star-Being petroform designated as Scorpius and Libra (see Figure 34).

Now perceived by visiting delegations of Cheyenne and Lakota as a place of 'origins', it is likely that the iconic Great Plains buffalo culture may have originated thousands of years earlier in the former prairie and open grasslands of southern Wisconsin. If true, 'the people' 
gathered at these places to seek blessings by enacting rituals timed to the seasonal movements of the sun and stars in order to ensure a successful hunt, fecundity and cosmic order. That order was set in stone.

\section{Acknowledgements}

I would like to thank Ralph Redfox, George Elk Shoulder, Dwight Bull Coming, Joe Walks Along and all the other Cheyenne visitors and guests who came over the years for their shared wisdom and knowledge. In addition, I extend my thanks to the Lakota Sicangu women Leola One Feather, Dinah Crow Dog, Lorraine Walking Bull and Anne White Hat for inviting me to their midwife and star conference at Bear Butte where they shared knowledge and stories concerning Lakota traditions and their perception of the stars. Although most have now passed on, they are remembered.

\section{References}

Abel, G.O. 1984, Realm of the Universe. Sanders College Publishing, Philadelphia, 466 p.

Allen, R.H. 1963, Star Names: Their Lore and Meaning. Dover Publications, New York, $563 \mathrm{p}$.

Aveni, A.F. 1972, Astronomical Tables for Use in Astro-Archaeological Studies. American Antiquity, 37(4): 531-540. doi:10.2307/278960

Behm, J., Bender, H.E., \& Farvour, F. 1989, The Krug petroform site in Fond du Lac County. Fox Valley Archeology, 14: 28-54.

Bender, H.E. 1992, Geophysical survey and investigation of a petroform site in Fond du Lac County Wisconsin. The Rock Art Quarterly, 3(Summer): 47-52.

Bender, H.E. 1994a, Unpublished field notes, In: Field Book No. 2, July 30, p. 68-71.

Bender, H.E. 1994b, Unpublished field notes, In: Field Book No. 2, August 22 to Sept 29, p. 83-95.

Bender, H.E. 1995a, Survey Results, Comments and Recommendations Regarding the Butternut-Auburn Transmission Line Project. Report on file at State Historical Society of Wisconsin, compliance chief; and Public Service Commission of Wisconsin, Madison, WI, $10 \mathrm{p}$.

Bender, H.E. 1995b, Unpublished field notes in Notebook No. 1, January 22, 77-78. Updated in unpublished field notes, Field Book No. 2, November 23, p. 121-122.

Bender, H.E. 2004, Star Beings and stones: Origins and legends. In: Indian Stories, Indian Histories (Giordano, F. \& Comba, E., Eds.), Otto Editore, Torino: p. 7-22.

Bender, H.E. 2007, Archeoastronomy investigations on petroform sites in the mid-continent of North America: A common sense approach with commentary. Part 1: The history, physical and fundamental factors in petroform site investigations. Journeys, The Journal of the Hanwakan Center for Prehistoric Astronomy, Cosmology and Cultural Landscape Studies, Inc., 2: 1-9.

Bender, H.E. 2008a, Seeking Place: Living on and Learning From the Cultural Landscape. In: The Archeology of Semiotics and the Social Order of Things (Nash, G. \& Children, G., Eds.), BAR International Series Vol. 1833, Archaeopress, Oxford: p. 45-70. 
Bender, H.E. 2008b, Medicine Wheels or 'Calendar Sites': Indian Time or the Space/Time Continuum. Time \& Mind: The Journal of Archaeology, Consciousness and Culture, 1(2): 195-206. doi:10.2752/175169708x309806

Bender, H.E. 2011a, Archeoastronomy investigations on petroform sites in the mid-continent (and latitudes) of North America: A common sense approach with commentary. Part 2: Practical or 'naked-eye' astronomy, (Unpublished manuscript), $51 \mathrm{p}$.

Bender, H.E. 2011b, Prominence and Presence: The Co-opting and Re-consecration of High Places in Southeastern Wisconsin. Time \& Mind: The Journal of Archaeology, Consciousness and Culture, 4(1): 7-30. doi:10.2752/175169711x12893985693559

Bender, H. E. 2011c, The Spirit of Manitou Across North America. In: Archaeology Experiences Spirituality? (Gheorghiu, D., Ed.), Cambridge Scholars Publishing, Newcastle upon Tyne: p. 143-177.

Bender, H.E. 2013, Bison Effigy Stones in Wisconsin. In: IFRAO (International Federation of Rock Art Organizations) 2013 Proceedings (Whitehead, P., Ed.), American Indian Rock Art Vol 40, American Rock Art Research Association, Albuquerque: p. 43-80.

Blakeslee, D.J., \& Blasing, R. 1988, Indian Trails in the Central Plains. Plains Anthropologist, 33(119): 17-25. URL: http://www.jstor.org/stable/25668732

Bloom, A.L, 1978, Geomorphology: A Systematic Analysis of Late Cenozoic Landforms. Prentice-Hall, Inc., Englewood Cliffs, New Jersey, 510 p.

Brumley, J.H. 1988, Medicine Wheels on the Northern Plains: A Summary and Appraisal. Archaeological Survey of Alberta Manuscript Series Vol. 12, Alberta Culture and Multiculturalism, Historical Resources Division, Edmonton, 127 p. URL: https://archive.org/details/medicinewheelson00brum

Buchner, A.P. 1980, Archeo-astronomical Investigations of the Petroform Phenomenon of Southeastern Manitoba. In: Directions in Manitoba Prehistory. Papers in Honor of Chris Vickers, (Pettipa, L., Ed.), Association of Manitoba Archaeologists and Manitoba Archaeological Society, Winnipeg: p. 89-109.

Callahan, K.L. 2004, The Jeffers Petroglyphs: Native American Rock Art on the Midwestern Plains. Prairie Smoke Press, St. Paul, Minnesota, 115 p.

Clayton, L., Attig, J.W., Mickelson D.M., Johnson, M.D., \& Syversib, K.M. 1991, Glaciation of Wisconsin, Educational Series Vol. 36, University of Wisconsin-Extension Geologic and Natural History Survey, Madison, Wisconsin, 4 p.

Cooper, J.M. 1975, The Gros Ventres of Montana: Part II Religion and ritual (Flannery R., Ed.), Anthropological Series Vol. 16, Catholic University of America Press, Washington D.C., 491 p.

Cornelius, G. 1997, The starlore handbook: An essential guide to the night sky. Chronicle Books, San Francisco, 176 p.

Denevan, W.M. 1992, The pristine myth: The landscape of the Americas in 1492. In: Annals of the Association of American Geographers, 82(3): 369-385. doi:10.1111/j.14678306.1992.tb01965.x

Eddy, J.A. 1974, Astronomical alignments of the Big Horn Medicine Wheel. Science, 184(4141): 1035-1043. doi:10.1126/science.184.4141.1035 
Eddy, J.A. 1977, Medicine wheels and Plains Indian astronomy. In: Native American Astronomy (Aveni A.P., Ed.), University of Texas Press, Austin: p. 147-169.

Ehlers, E.G., \& Blatt, H. 1982, Petrology - Igneous, sedimentary, and metamorphic. W. H. Freeman and Company, New York, 732 p.

Garvie, S.J. 1991, Whiteshell petroforms and plains medicine wheels: Sunrise alignments in different contexts. Manitoba Archaeological Journal, 1(2): 95-112.

Goldstein, L. 1983, The Southeast Wisconsin Archaeological Project: 1982-1983. Reports of Investigations Vol. 68, Archaeological Research Laboratory, University of Wisconsin, Milwaukee, $281 \mathrm{p}$.

Goldstein, L. \& Kind, R. 1983, The early vegetation of the region. In: The Southeast Wisconsin Archaeological Project: 1982-1983 (Goldstein, L., Ed.), Reports of Investigations Vol. 68, Archaeological Research Laboratory, University of Wisconsin, Milwaukee: p. 17-45.

Goldstein, L.G., \& Osborn, S.K. 1988, A guide to common prehistoric projectile points in Wisconsin. Milwaukee Public Museum, Milwaukee, 74 p.

Goodman, R. 1992, Lakota star knowledge: Studies in Lakota Stellar Theology. Sinte Gleska University, Rosebud, South Dakota, 64 p.

Grant, B. 2000, Concise Encyclopedia of the American Indian. Wings Books, New York, $352 \mathrm{p}$.

Gribbin, J. 1996, Companion to the Cosmos. Little, Brown and Company, Boston, 504 p.

Grinnell, G.B. 1972, The Cheyenne Indians: Their history and way of life. Volume II. University of Nebraska Press, Lincoln, 429 p.

Hewes, G. 1948, Early Tribal Migrations in the Northern Great Plains. Plains Archaeological Conference News Letter, 1(4): 49-61. URL: http://www.jstor.org/stable/25664687

Hoebel, E.A. 1960, The Cheyennes-Indians of the Great Plains. Holt, Rinehart and Winston, New York, 103 p.

Kehoe, T.F. 1965, Indian Boulder Effigies. Popular Series Vol. 12, Saskatchewan Museum of Natural History, Regina, 15 p.

Kehoe, A.B. 1992, Clot-of-Blood. In: Earth \& Sky (Williamson, R.A., \& Farrer, C.R., Eds.), University of New Mexico Press, Albuquerque: p. 207-214.

Kehoe, T. F. \& Kehoe, A. B. 1977, Stones, Solstices and Sun Dance Structures. Plains Anthropologist Journal of the Plains Conference, 2(76) Pt.1: 85-96. doi:10.2307/25667371

King, J.F. 1981, Late Quaternary Vegetational History of Illinois. Ecological Monographs, 5 (1): 43-62. doi:10.2307/2937306

Krupp, E.C., 1991, Beyond the Blue Horizon. Oxford University Press, New York, 387 p.

LaBerge, G.L. 1994, Geology of the Lake Superior Region. Geoscience Press Inc., Phoenix, Arizona, 313 p.

Lewis, T.H. 1886, Mounds on the Red River of the North. The American Antiquarian and Oriental Journal, 8(6): 369-371.

URL: https://archive.org/details/americanantiqua27peetgoog 
Lewis, T.H. 1889, Stone Monuments in South Dakota. American Anthropologist, 2: 159-167. doi:10.1525/aa.1889.2.2.02a00040

Lewis, T.H. 1890, Stone Monuments in N. W. Iowa \& S. W. Minnesota, American Anthropologist, 3: 269-279. doi:10.1525/aa.1890.3.3.02a00090

Lewis, T.H. 1891, Boulder Outline Figures in the Dakotas, Surveyed in the Summer of 1890. American Anthropologist, 4: 19-24. doi:10.1525/aa.1891.4.1.02a00030

Lothson, G.A. 1976, The Jeffers Petroglyphs Site: A survey and analysis of the carvings. Minnesota Archaeology Series Vol. 12, Minnesota Historical Society, St. Paul, 52 p.

Mails, T.E. 1972, The Mystic Warriors of the Plains: The Culture, Arts, Crafts, and Religion of the Plains Indians. Doubleday, New York, 618 p.

Mails, T.E. 1973, Plains Indians: Dog Soldiers, Bear Men and Buffalo Women. Bonanza Books, New York, 384 p.

Marriott, C. 2001. SkyMap Pro Version 8. SkyMap Astronomy Software, Cheshire, England. URL: http://www.skymap.com/

Meeus, J.M. 1991, Astronomical algorithms. Willmann-Bell Inc., Richmond, Virginia, 429 p.

Meeus, J.M. 1997, Mathematical astronomy morsels. Willman-Bell, Inc. Richmond, Virginia, $379 \mathrm{p}$.

Nabokov, P. 1967, Two Leggings: The Making of a Crow Warrior. University of Nebraska Press, Lincoln, 216 p.

Owusu, H. 1997, Symbols of Native America. Sterling Publishing Co., New York, 320 p.

Powell, P.J. 1969, Sweet medicine, Vol. 2. University of Oklahoma Press, Norman, 503 p.

Powers, W.K. 1977, Oglala religion. University of Nebraska Press, Lincoln, 237 p.

Quimby, G.I. 1960, Indian life in the upper Great Lakes. University of Chicago Press, Chicago, $182 \mathrm{p}$.

Rosholt, M., \& Gehl, J.B. 1976, Florimund J. Bonduel, Missionary to Wisconsin Territory. Rosholt House, Palmer Publications, Amherst, 238 p.

Schlesier, K.H. 1987, The wolves of heaven. Cheyenne shamanism, ceremonies, and prehistoric origins. University of Oklahoma Press, Norman, 214 p.

Sesti, G.M. 1991, Glorious Constellations: History and Mythology. Henry N. Abrams, New York, $495 \mathrm{p}$.

Spence, L. 1994, Myths of the North American Indians. Gramercy Books, New York, 393 p.

Steinbring, J. 1970a, The Tie Creek Boulder Site of Eastern Mantibo. In: Ten Thousand Years: Archaeology in Manitoba (Haldy, W., Ed.), Manitoba Archaeological Society, Winnipeg: p. 223-269.

Steinbring, J. 1970b, Evidences of Old Copper in a Northern Transition Zone. In: Ten Thousand Years: Archaeology in Manitoba (Haldy, W., Ed.), Manitoba Archaeological Society, Winnipeg: p. 47-75.

Steinbring, J. 1992, Phenomenal Attributes: Site Selection Factors in Rock Art. American Indian Rock Art, 17: 102-113.

Steinbring, J. 1997, Successful rock art conservation projects: Two cases. Pictogram (Southern African Rock Art Research Association), 9(2): 21-27. 
Steinbring, J. 1999, Early rock art of mid-continental North America. In: Dating and the earliest Known rock art (Strecker, M., \& Bahn, P., Eds.), Oxbow Books, Oxford: p. 514.

Steinbring, J., Behm, J., \& Bender, H.E. 1995, Petroform research in the North American Interior. Report on file at State Historical Society of Wisconsin, compliance chief; and Public Service Commission of Wisconsin, Madison, 35 p.

Steinbring, J., \& Buchner, A.P. 1997, Cathedrals of prehistory: Rock art sites of the Northern Plains. American Indian Rock Art, 23: 73-84.

Steinbring, J., Behm, J., \& Bender, H.E. 2003, Petroforms in the North American MidContinent: A Neglected Phenomenon. In: American Indian Rock Art, 23: 111-120.

Steinbring, J., \& Steinbring, S. 1999. Phenomenal Attributes and Elemental Forms in the Rock Art Ritualism of Western South Dakota and Eastern Wyoming, U.S.A. Pictogram, 11(2): 6-11.

Stoltman, J.B. 1986, The Archaic Tradition. The Wisconsin Archeologist, 67(3-4): 207-238.

Sundstrom, L. 2004, Storied Stone: Indian Rock Art of the Black Hills, University of Oklahoma Press, Norman, 238 p.

Sutton, R. 1965, The Whiteshell Boulder Mosaics. Manitoba Archaeological Newsletter, 2(1): 2-11.

Syverson, K.M., \& P.M. Colgan, 2011, The Quaternary of Wisconsin: An Updated Review of Stratigraphy, Glacial History and Landforms. In: Quaternary Glaciations - Extent and Chronology, A Closer Look (Ehlers, J., Gibbard, P.L. \& Hughes, P.D., Eds.), Developments in Quaternary Science Vol. 15, Elsevier, Amsterdam: p. 537-552.

Taylor, C.F., \& Sturtevant, W.C. 1996, The Native Americans. Smithmark Publishers, New York, $512 \mathrm{p}$.

Thomas, C. 1894, Report on the Mound Explorations of the Bureau of Ethnology. Twelfth Annual Report of the Bureau of Ethnology of the Secretary of the Smithsonian Insitution, 1890-'91. Government Printing Office, Washington, D.C., 742 p.

Waldman, C. 1985, Atlas of the North American Indian. Facts on File, New York, 276 p.

Williamson, R.A. 1989, Living the sky: The cosmos of the American Indian. University of Oklahoma Press, Norman, 366 p. 